\title{
ÉVOLUTION DE LA PRATIQUE DE LA COMMISSION BANCAIRE (1935-1975)
}

Thibaud Giddey

CRISP | «Courrier hebdomadaire du CRISP »

$2017 / 34 n^{\circ} 2359-2360$ | pages 5 à 58

ISSN 0008-9664

Article disponible en ligne à l'adresse :

https://www.cairn.info/revue-courrier-hebdomadaire-du-crisp-2017-34-page-5.htm

Distribution électronique Cairn.info pour CRISP.

(C) CRISP. Tous droits réservés pour tous pays.

La reproduction ou représentation de cet article, notamment par photocopie, n'est autorisée que dans les limites des conditions générales d'utilisation du site ou, le cas échéant, des conditions générales de la licence souscrite par votre établissement. Toute autre reproduction ou représentation, en tout ou partie, sous quelque forme et de quelque manière que ce soit, est interdite sauf accord préalable et écrit de l'éditeur, en dehors des cas prévus par la législation en vigueur en France. Il est précisé que son stockage dans une base de données est également interdit. 
Courrier hebdomadaire

$$
\mathrm{n}^{\circ} 2359-2360 \cdot 2017
$$

\section{Évolution de la pratique de la Commission bancaire (1935-1975)}

Thibaud Giddey 


\section{Courrier hebdomadaire}

Rédacteur en chef : Cédric Istasse

Assistante éditoriale : Fanny Giltaire

Le Courrier hebdomadaire est soutenu par l'Administration générale de l'Enseignement et de la Recherche scientifique de la Fédération Wallonie-Bruxelles. Il est également publié avec l'aide financière du Fonds de la recherche scientifique-FNRS.

Une version numérique du Courrier hebdomadaire est disponible en pay per view (au numéro) et en accès gratuit pour les abonnés sur le site portail de CAIRN (http://www.cairn.info).

Le numéro simple : 6,90 euros - le numéro double : 12,40 euros

Abonnement : 235,00 euros

Souscription, commandes et informations :

CRISP - Place Quetelet, 1A - 1210 Bruxelles

Tél : 32 (0)2 2110180 - Fax : 32 (0)2 2197934

http://www.crisp.be - info@crisp.be

IBAN BE51 310027157662 - Swift BBRUBEBB

Éditeur responsable : Jean Faniel - Place Quetelet, 1A - 1210 Bruxelles

Tous droits de traduction, d'adaptation ou de reproduction par tous procédés, y compris la photographie et le microfilm, réservés pour tous pays.

ISSN 00089664 


\section{TABLE DES MATIÈRES}

INTRODUCTION

1. L'ASSERMENTATION DES RÉVISEURS ET L'ACTIVITÉ RÉVISORALE 6

1.1. L'assermentation des réviseurs par la Commission bancaire 7

$\begin{array}{ll}\text { 1.2. Les réviseurs de la Banque de la Société générale } & 13\end{array}$

2. LES COEFFICIENTS BANCAIRES ET COEFFICIENTS DE RÉSERVE 16

\begin{tabular}{ll}
\hline 2.1. L'ancrage juridique des coefficients & 17
\end{tabular}

2.2. Premières mises en œuvre des coefficients par la Commission bancaire $\quad 18$

2.3. L'évolution des coefficients bancaires (1946-1975) 21

2.4. Les coefficients bancaires : un bilan 27

3. L'APPLICATION DE L'AUTONOMIE BANCAIRE ET LES MESURES SUR LA SCISSION $\quad 29$

3.1. L'autonomie bancaire dans la réglementation des années 1930 et les difficultés initiales de mise en œuvre par la Commission bancaire 29

3.2. L'affaire Brufina et l'autonomie bancaire dans les années 1950

3.3. Le protocole sur l'autonomie bancaire de novembre 1960

3.4. L'affaire Bonvoisin-Brockville $\quad 37$

3.5. Le protocole sur l'autonomie bancaire de février 1974

4. L'EXTENSION DES DOMAINES DE COMPÉTENCES DE LA COMMISSION BANCAIRE (1957-1975) $\quad 44$

4.1. Les fonds communs de placement 45

4.2. Le contrôle des entreprises qui collectent des fonds en faisant appel au public (1964)

4.3. La réglementation sur les sociétés à portefeuille ou holdings (1967) 48

4.4. Le contrôle des caisses d'épargne privées et la loi Mammouth (1975) 50

CONCLUSION GÉNÉRALE $\quad 53$ 


\section{INTRODUCTION}

Dans quelles conditions naissent les régimes de supervision bancaire ? Comment les choix institutionnels opérés lors de l'instauration d'un régime de régulation influencent-ils son évolution ultérieure ? Qui sont les acteurs de la surveillance bancaire? Quel écart sépare les législations sur le contrôle des banques de leur mise en œuvre effective?

C'est à répondre à ces principales questions que s'attachent deux livraisons successives du Courrier hebdomadaire. La précédente se concentrait sur une présentation de la genèse de la Commission bancaire dans les années 1930, ainsi que de son statut juridique, de sa composition et de ses moyens ${ }^{1}$. La présente est relative à l'évolution de la pratique de la Commission bancaire entre 1935 et 1975. En effet, il s'agit désormais d'examiner les activités concrètes de l'autorité de régulation du monde bancaire belge au cours de ses quarante premières années d'existence. Le choix d'interrompre notre analyse historique au milieu des années 1970 repose, d'une part, sur l'importante réforme législative opérée à ce moment-là et, d'autre part et plus généralement, sur l'entrée qu'effectue alors le monde financier dans une nouvelle ère marquée par une plus forte instabilité et une plus forte européanisation et mondialisation ${ }^{2}$.

Dans ce cadre, nous avons sélectionné quatre domaines thématiques bien précis pour illustrer les activités de la Commission bancaire entre 1935 et 1975. Les trois premiers ont trait à des compétences que l'arrêté royal du 9 juillet 1935 avait directement confiées à cet organisme. Primo, il sera question de l'assermentation des réviseurs par la Commission bancaire, réviseurs auxquels le régime de surveillance délègue la mission de contrôler directement les banques. Secundo, nous passerons en revue le problème, d'apparence technique mais en vérité très politique dans sa portée, de la détermination par la Commission bancaire des coefficients bancaires - ces proportions légales entre divers éléments du bilan censées renforcer la protection des déposants. Tertio, nous examinerons la délicate question de l'exécution des mesures visant à réaliser la séparation entre les banques de dépôt et le groupe financier auquel elles appartenaient avant 1934 ; autrement dit, il s'agit de la négociation de ce que la Commission bancaire appelle les protocoles sur l'autonomie bancaire, des accords contractuels privés négociés avec les deux plus grands groupes et leurs filiales bancaires respectives (Société générale de Belgique - Banque de la Société générale de Belgique, Brufina - Banque de Bruxelles). Quarto et enfin, nous aborderons l'élargissement des compétences de la Commission bancaire qui est opéré entre la fin des années 1950 et le milieu des années 1970, notamment dans le domaine des fonds de placement, des appels publics au crédit et du contrôle des caisses d'épargne privées.

* Cette étude est issue d'une thèse de doctorat en histoire contemporaine soutenue en 2017 à l'Université de Lausanne sous la direction de Malik Mazbouri et intitulée Surveiller et servir : la Commission fédérale des banques et la régulation des banques en Suisse. Le soutien du Fonds national suisse de la recherche scientifique (FNS) a rendu possibles les recherches menées en Belgique. Je remercie Guy Vanthemsche pour ses commentaires avisés et son aide dans l'élaboration de cette étude.

T. GIDDEY, «Formation et spécificités historiques de la Commission bancaire (1935-1975) », Courrier hebdomadaire, CRISP, $\mathrm{n}^{\circ}$ 2357-2358, 2017.

2 C. KoBraK, «From Multinational to Transnational Banking», in Y. CAssis, R. S. Grossman, C. R. SCHENK (dir.), The Oxford Handbook of Banking and Financial History, Oxford, Oxford University Press, 2016, p. 163-190. 


\section{L'ASSERMENTATION DES RÉVISEURS ET L'ACTIVITÉ RÉVISORALE}

Selon le rapport au Roi, c'est-à-dire l'exposé des motifs, qui accompagne l'arrêté royal du 9 juillet 1935, rédigé par le futur président de la Commission bancaire Eugène de Barsy, les réviseurs assermentés - une nouvelle fonction instituée par la réglementation - exercent un double rôle. "D'un côté, ils rempliront avec plus d'efficacité les fonctions actuelles des commissaires et des fonctions analogues là où la loi n'avait pas organisé ce mode de surveillance. (...) D'autre part, ils auront pour mission de signaler à la Commission bancaire les infractions qu'ils constateraient dans l'exécution de leur mission ${ }^{3}$. Dans l'esprit des législateurs belges, ces fameux réviseurs - inspirés de leur équivalent helvétique officialisé dans la loi fédérale du 8 novembre 1934 - reprennent le mandat privé qui échoit, selon le droit des sociétés, aux commissaires dans toute autre entreprise ${ }^{4}$. En outre, ils exercent une fonction presque publique, en agissant en collaboration avec la Commission bancaire et en pratiquant annuellement l'audit de la comptabilité bancaire pour assurer que les dispositions légales y sont respectées. Le rapport au Roi se veut d'emblée rassurant, en précisant la portée du contrôle de ces réviseurs : «Ils n'auront aucune mission d'ordre fiscal. Il est entendu, et il convient d'affirmer de la façon la plus catégorique et la plus claire, que ces réviseurs n'auront aucunement à se préoccuper, sauf le cas de fraude ou d'insolvabilité, des relations existant entre les banques et leurs déposants. Ceux-ci seront totalement ignorés de la Commission bancaire, qui n'aura jamais à s'occuper, à aucun titre, ni de l'origine, ni de la consistance, ni des mouvements de dépôts individuels $»^{5}$.

Le ton impérieux de cette déclaration sur le caractère inoffensif du contrôle de réviseur à l'égard d'éventuels fraudeurs fiscaux peut surprendre. Un juriste français salue cette clause en 1937, estimant que "l'agitation du spectre redoutable du "cadastre des fortunes" pouvait en effet entraîner des troubles graves dans l'économie financière et bancaire " ${ }^{6}$. Cette attitude contraste sans aucun doute avec l'esprit qui régnera lors de la redéfinition de l'activité révisorale en 1975. En effet, dans le cadre de l'élaboration de ce qui deviendra

3 Arrêté royal du 9 juillet 1935 sur le contrôle des banques et le régime des émissions de titres et valeurs, Moniteur belge, 10 juillet 1935, rapport au Roi.

4 Sur l'influence du régime de régulation bancaire suisse, cf. T. GIDDEY, « La surveillance bancaire belge de 1935 façonnée sur le modèle suisse : un discret transfert de politique publique ? ", Revue belge de philologie et d'histoire, volume 92, n' 4, 2014, p. 1211-1243.

Arrêté royal du 9 juillet 1935 sur le contrôle des banques et le régime des émissions de titres et valeurs, Moniteur belge, 10 juillet 1935, rapport au Roi.

6 M. Allemandet, Le contrôle des banques en Belgique, Paris, Librairie technique et économique, 1937, p. 159. 
la loi du 30 juin 1975 relative au statut des banques, des caisses d'épargne et de certains autres intermédiaires financiers (dite loi Mammouth), la stricte séparation entre le contrôle bancaire et la fraude fiscale est remise en question. Cette évolution est rendue possible par l'ouverture, en 1975, d'instructions judiciaires au sujet de transfert de fonds vers l'étranger, qui donne l'occasion à l'opposition socialiste, par la voix d'André Cools, d'interpeller le gouvernement Tindemans I (formé d'une coalition des partis sociauxchrétiens et libéraux) à ce propos ${ }^{7}$. Mis sous pression, l'exécutif intègre alors un amendement qui autorise la Commission bancaire à déroger au principe de nonintervention dans les questions fiscales, si elle apprend qu'une banque « aurait mis en place un mécanisme particulier ayant pour but ou pour effet de favoriser la fraude fiscale par des tiers ${ }^{8}$. Mais avant cette réforme, soit pendant quarante ans, le droit de veto dont disposent les réviseurs de banques lorsqu'ils constatent une infraction pénale ne s'applique pas aux délits fiscaux.

\subsection{L'ASSERMENTATION DES RÉVISEURS PAR LA COMMISSION BANCAIRE}

Toujours selon le régime de l'arrêté royal du 9 juillet 1935, la Commission bancaire est chargée de procéder à l'assermentation des individus qu'elle juge dignes d'exercer la fonction de réviseur bancaire. C'est elle qui dresse la liste des réviseurs assermentés et en fixe les rémunérations. En revanche, jusqu'en 1975 au moins, les banques désignent librement leur(s) réviseur(s) parmi la liste des contrôleurs assermentés ${ }^{9}$. Les critères d'admission et d'indépendance liés au statut de réviseur sont également stipulés. Les réviseurs ne peuvent exercer aucune autre fonction dans les banques soumises à leur surveillance, ni aucune autre fonction rémunérée par l'État, les provinces ou les communes, ni aucune fonction dirigeante (administrateur, directeur, gérant ou fondé de pouvoir) d'une société commerciale. Ils ne peuvent accepter aucun avantage, en dehors de la rémunération fixe, de la part de la banque contrôlée ; une banque n'est pas non plus autorisée à consentir des prêts aux réviseurs qui exercent leurs fonctions auprès d'elle. Enfin, les réviseurs sont soumis à un secret professionnel, en dehors des obligations légales ou judiciaires.

Dans un règlement ad hoc publié en novembre 1935, la Commission bancaire précise encore les critères d'admission à la fonction de réviseur : il faut être de nationalité belge, être âgé de 30 ans au moins et de 65 au plus, être porteur d'un diplôme d'enseignement supérieur qui soit en rapport avec la fonction à exercer, bénéficier d'une expérience

Chambre des représentants, Annales parlementaires, n 83, 25 mars 1975, p. 2302-2306. Cf. A. BRUYNEEL, «La loi du 30 juin 1975 : mammouth, souris ou pot-pourri ? », Journal des tribunaux, volume 90, $\mathrm{n}^{\circ} 4931$, 1975 , p. 650.

8 Article 39, alinéa 2, de l'arrêté royal du 9 juillet 1935 sur le contrôle des banques et le régime des émissions de titres et valeurs, introduit par la loi du 30 juin 1975. Pour des précisions sur ce mécanisme et une liste de comportements répréhensibles, cf. Commission bancaire, Rapport annuel, 1975-1976, p. 44-48.

9 Avec les amendements de la loi du 30 juin 1975, la Commission bancaire obtient officiellement un droit d'approbation du choix d'un réviseur par une banque (cf. infra). 
professionnelle de cinq ans au moins et d'une moralité irréprochable ${ }^{10}$. Ce n'est qu'en décembre 1967 que ce régime d'admission connaît une refonte, dans le sens d'" adaptations rendues souhaitables par l'évolution des conditions de recrutement et de carrière des réviseurs " ${ }^{11}$. Les nouveaux critères rendent la sélection plus restrictive : la jouissance des droits civils et politiques devient nécessaire, l'âge maximal au moment de l'agréation baisse de 65 à 50 ans, les candidats condamnés pour infraction à la législation financière sont exclus, et il n'y a plus d'exceptions possibles pour des candidats étrangers résidant en Belgique ou ne disposant pas de titres universitaires adéquats. Un seul assouplissement est à signaler, à savoir le fait que les incompatibilités établies en 1935 sur les liens de parenté entre un réviseur et les dirigeants d'une banque qu'il contrôle disparaissent.

L'assermentation des réviseurs est une mission essentielle pour la Commission bancaire. En effet, il s'agit pour elle d'une des rares possibilités offertes par la loi d'influencer, certes très indirectement, la qualité de la vérification des écritures effectuée annuellement. "Dépourvue de moyens d'investigations et, dès lors, de contrôle direct, la Commission bancaire n'est en mesure d'assumer ses responsabilités que par la surveillance dont la loi la charge sur les réviseurs placés en première ligne dans l'organisation du contrôle ", résume un collaborateur de la Commission bancaire, Jean Le Brun, en $1971^{12}$. Quant aux missions confiées aux réviseurs, elles dépassent de fait la simple vérification comptable et s'étendent à l'examen du respect continu des lois, règlements et statuts (dont les prescriptions sur les fonds propres, par exemple).

Rapidement, dans la mise en application de ces dispositions sur le contrôle révisoral, la Commission bancaire est confrontée à des difficultés qui ont trait à la fois au mode de désignation des réviseurs, au nombre de réviseurs assermentés et à leurs compétences, ces trois points étant liés entre eux. D'emblée, la Commission bancaire n'est pas convaincue par le bien-fondé du système de contrôle indirect et du régime qui permet aux banques de désigner elles-mêmes leur(s) réviseur(s). Dans son premier rapport annuel, l'autorité de surveillance avance : "Il ne paraît pas douteux qu'un contrôle plus efficace aurait été exercé plus rapidement, peut-être à moindres frais, si la Commission bancaire avait pu constituer elle-même un corps de réviseurs entre lesquels elle aurait réparti les travaux. (...) La conséquence [du refus de ce pouvoir] est que l'indépendance des réviseurs ne peut être assurée que d'une manière indirecte. Il en est d'ailleurs de même de leur compétence $"{ }^{13}$. Ces regrets amers ne débouchent pourtant pas sur une tentative de la Commission bancaire de modifier dans la loi le régime de surveillance. Elle adapte plutôt progressivement sa politique d'assermentation des réviseurs et son action de recommandation informelle auprès des banques lors du choix des réviseurs.

10 Arrêté ministériel du 22 novembre 1935, Moniteur belge, 24 novembre 1935, règlement d'agréation des réviseurs. Cf. aussi H. DE SMEDT, Regards rétrospectifs sur les origines et l'évolution du rôle et de la fonction des réviseurs agréés et sur la contribution de leur institut au contrôle prudentiel en Belgique, Bruxelles, Institut des réviseurs d'entreprises, 2010, p. 24-25.

11 Commission bancaire, Rapport annuel, 1966-1967, p. 53. L'arrêté de la Commission bancaire du 19 décembre 1967 "portant règlement d'agréation des réviseurs de banques » figure en annexe de ce rapport annuel (aux pages 226-229).

J. LE BRUN, « Nature et modalités juridiques du contrôle revisoral des banques », Reflets et perspectives de la vie économique, $\mathrm{n}^{\circ} 1,1971, \mathrm{p} .32$.

13 Commission bancaire, Rapport annuel, 1936, p. 42. 
Le graphique 1 présente l'évolution entre 1936 et 1975 du nombre de réviseurs assermentés par la Commission bancaire, de la part de ces réviseurs effectivement désignés par une ou plusieurs banques et de l'effectif des banques soumises au contrôle.

Graphique 1. Nombre de réviseurs agréés, réviseurs actifs et nombre de banques (1936-1975)

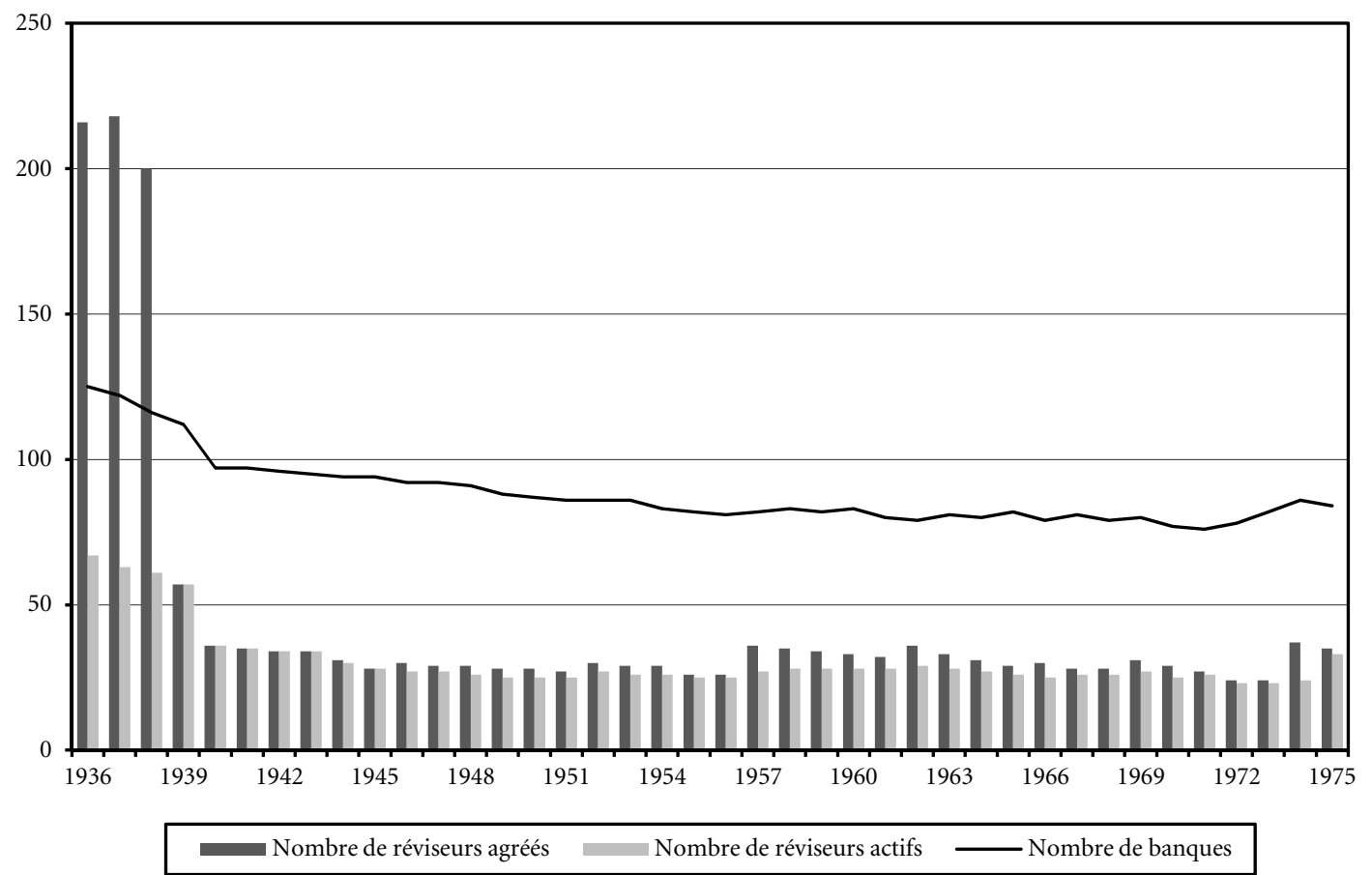

Sources : Rapports annuels de la Commission bancaire pour les années correspondantes.

Le graphique 1 met en évidence le changement qu'a opéré la Commission bancaire entre 1938 et 1940 dans sa politique d'agréation des réviseurs. Alors que, entre 1936 et 1938, elle avait accordé à plus de 200 réviseurs le droit de figurer sur la liste de comptables autorisés à pratiquer la révision bancaire - dont $30 \%$ seulement étaient effectivement actifs auprès de banques -, ce chiffre passe à 57 en 1939, puis à 36 en 1940, avant de se stabiliser autour d'une trentaine de réviseurs durant les Trente Glorieuses ${ }^{14}$.

Dans les faits, la chute spectaculaire du nombre de réviseurs assermentés en 1939 est provoquée par des scandales bancaires qui éclatent à ce moment-là. Les difficultés de la Caisse générale de reports et de dépôts (une filiale de la Société générale) - elles-mêmes entraînées par la cessation de paiement de la banque privée Mendelssohn \& $\mathrm{C}^{\mathrm{ie}}$ - et la faillite du Crédit anversois en 1939 ont montré les limites du système de surveillance. Ces deux effondrements, qui relancent dans la presse la discussion sur l'utilité de la Commission bancaire, suscitent aussi un débat interne sur le rôle des réviseurs. Dans son rapport annuel pour 1939, la Commission bancaire avoue très sobrement que

14 Une première sélection avait déjà été effectuée lors de la première assermentation officielle, puisque la Commission bancaire avait reçu 412 demandes d'agréation à la fin du mois de septembre 1936, dont elle n'avait retenu que 216 candidatures (cf. Commission bancaire 1935-1960, Bruxelles, Commission bancaire, 1960, p. 119). 
«l'expérience de certaines difficultés bancaires survenues récemment est venue confirmer (...) que le régime des réviseurs (...) n'assurait pas au contrôle des banques l'efficacité désirable ${ }^{15}$. Plus précisément, le président de la Commission bancaire, Maurice Frère, confirme, dans une lettre au procureur du Roi, à la fois l'incompétence et le manque d'indépendance du réviseur en charge de la Caisse générale de reports et de dépôts : «Le réviseur a toléré, sans l'en aviser, l'existence d'un risque tout à fait hors de proportion avec les dépôts confiés à la banque, risque que les documents régulièrement communiqués à la [Banque nationale de Belgique (BNB)] ne permettaient pas d'apercevoir. En outre, [la Commission bancaire] a constaté certaines inexactitudes matérielles dans les documents ainsi communiqués, alors que, dans ses rapports trimestriels, le réviseur certifiait les avoir vérifiés. Elle a estimé enfin que, d'une manière générale, le réviseur avait fait preuve, dans l'accomplissement de sa mission, d'un manque d'indépendance manifeste à l'égard des dirigeants de la banque $»{ }^{16}$.

À la suite de ces expériences malheureuses, la Commission bancaire décide de modifier sa politique d'assermentation des réviseurs. Par un arrêté ministériel du 20 octobre 1939, elle obtient le pouvoir de limiter le nombre de candidats réviseurs sur lequel le choix des banques pourra se porter ${ }^{17}$. L'idée est d'améliorer l'indépendance du réviseur à l'égard de la banque qu'il contrôle. En effet, la présence de nombreux candidats réviseurs pour un petit nombre de mandats potentiels, selon le régime d'avant 1939, signifiait qu'un réviseur dépendait de l'obtention ou du maintien d'un mandat pour conserver sa situation matérielle. Comme l'exprime un bref commentaire paru dans le quotidien Le Soir du 15 juillet 1939, « on a mis les réviseurs dans une tour d'ivoire sans trop songer que, dans une pareille tour, on peut bien mourir de faim ${ }^{18}$.

Le premier numerus clausus est fixé à 36 en 1941, puis varie légèrement selon la volonté de la Commission bancaire de l'adapter à la hausse ou à la baisse, comme il ressort du graphique 1. La formation de ce nouveau corps de comptables spécialisés conduit en outre à la constitution d'une organisation corporative. En mars 1937, sous les auspices de la Commission bancaire qui la soutient financièrement, l'Association belge des réviseurs voit le jour; en octobre 1940, elle se transforme en une union professionnelle dénommée Institut belge des réviseurs ${ }^{19}$. L'objectif principal de cette organisation est d'assurer la formation continue de ses membres. Ce groupement connaît un remaniement avec la loi du 22 juillet 1953, qui professionnalise et officialise le rôle des réviseurs d'entreprise et crée un Institut des réviseurs d'entreprise ${ }^{20}$. Cette professionnalisation croissante opérée au cours des années 1950 et 1960 se reflète aussi dans le domaine plus particulier du

15 Commission bancaire, Rapport annuel, 1939, p. 29.

Archives de la Banque nationale de Belgique [= ABNB], J327/17, Lettre de M. Frère au procureur du Roi W. Ganshof van der Meersch, 17 novembre 1939. Le réviseur en question, Camille Lanscotte, fait les frais du durcissement de la politique d'agréation et disparaît des listes des réviseurs agréés en 1940.

7 Arrêté ministériel du 20 octobre 1939 approuvant les modifications du règlement d'agréation des réviseurs, Moniteur belge, 25 octobre 1939. Cf. aussi ABNB, J327/5-9.

18 Le Soir, 15 juillet 1939.

19 Commission bancaire, Rapport annuel, 1937, p. 137-139. Cf. aussi D. PONLOT, Le statut légal des banques et le contrôle des émissions de titres et valeurs, Court-Saint-Étienne, Émile Oleffe, 1958 ; H. DE SMEDT, Regards rétrospectifs sur les origines et l'évolution du rôle et de la fonction des réviseurs agréés et sur la contribution de leur institut au contrôle prudentiel en Belgique, op. cit., p. 29-62.

20 Cf. «Les réviseurs d'entreprises », Courrier hebdomadaire, CRISP, n 251, 1964, p. 1-22. 
contrôle bancaire : en 1971, tous les réviseurs agréés par la Commission bancaire sont également des « réviseurs d'entreprise » reconnus par la loi du 22 juillet $1953^{21}$.

Un second problème est rapidement identifié par la Commission bancaire dans le régime de surveillance par les réviseurs de banque. Il s'agit de la disposition qui autorise les banques à choisir librement leur(s) réviseur(s) parmi la liste des experts assermentés. Dès son premier rapport annuel, en 1936, la Commission bancaire critique ce système, qui ne lui semble pas à même d'assurer l'indépendance et la compétence du corps de réviseurs (cf. supra). Elle n'est pas la seule. Le quotidien de tendance catholique La Libre Belgique met à mal le système de désignation des contrôleurs dans un article de février 1936 : «Voici donc un homme qui a reçu pour mission de surveiller un établissement de crédit déterminé ; et cette mission comporte un salaire appréciable. Mais il appartient aux dirigeants de l'établissement contrôlé de le nommer et, s'il leur plaît, de le congédier du jour au lendemain. Quelle tentation pour les banquiers de choisir, sur la liste de la Commission bancaire, des gens sur l'indolence ou la facilité de caractère ou la discrétion particulière desquels ils croiront pouvoir compter (...). Il suffira peut-être de quelques choix individuels maladroits, ou surtout trop adroits, pour ériger, aux yeux du public, en signe distinctif d'une indépendance suréminente, le fait d'être rangé au nombre des réviseurs redoutés, donc les moins souvent choisis, plutôt qu'au nombre des plus recherchés et des plus fréquemment préférés ${ }^{22}$.

Face à ce qu'elle considère comme une imperfection de la législation, la Commission bancaire développe une politique de recommandation informelle pour influencer le choix des réviseurs par les banques. C'est ce qu'exprime le collaborateur de la Commission bancaire J. Le Brun en 1971 : «La Commission bancaire, confrontée à l'origine avec les problèmes découlant du nombre excessif des réviseurs et des atteintes à leur indépendance qui pouvaient en résulter, avait considéré qu'elle était en droit de refuser l'admission au serment lorsque la désignation ne recueillait pas son assentiment. Elle en avait tiré que la révocation du réviseur par la banque était soumise à son accord ${ }^{23}$. Ce faisant, la Commission bancaire est en porte-à-faux vis-à-vis du système légal de désignation. Malgré l'absence de support juridique, la Commission bancaire maintient une procédure de consultation qui précède la nomination d'un réviseur auprès d'une banque. En avril 1946, le président E. de Barsy confirme que la Commission bancaire, en faisant des "suggestions très marquées lors du choix des réviseurs par les banques ", a modifié la philosophie du système de désignation ${ }^{24}$. En 1960 encore, la Commission bancaire avoue avoir adopté " une procédure officieuse » de consultation ${ }^{25}$. Cette façon d'influencer informellement le choix des réviseurs se maintient pendant toute la période examinée. En 1974, le rapport annuel de la Commission bancaire affirme ainsi : « Les banques sont libres de choisir leur réviseur parmi ceux que la Commission a agréés et celle-ci n’a pas

\footnotetext{
J. LE BRUN, « Nature et modalités juridiques du contrôle revisoral des banques », op. cit., p. 35.

La Libre Belgique, 9-10 février 1936.

J. LE BRUN, "Nature et modalités juridiques du contrôle revisoral des banques », op. cit., p. 40-41.

E. de Barsy indique : «L'ensemble des dispositions que la Commission bancaire a prises jusqu'ici (réduction considérable de la liste des réviseurs, élimination progressive de ceux qui ne se consacrent pas principalement à l'action révisorale, suggestions très marquées lors du choix des réviseurs par les banques, etc.) a déjà donné à la fonction de réviseur un caractère sui generis très différent de la conception qui a prévalu lors de la rédaction de l'arrêté [royal du 9 juillet 1935] » (Archives générales du royaume [= AGR], Commission bancaire, financière et des assurances $[=\mathrm{CBFA}], 147$, Procès-verbal de la Commission bancaire, 23 avril 1946).

Commission bancaire 1935-1960, op. cit., p. 121.
} 
juridiquement le pouvoir de se prononcer cas par cas sur la désignation qu'une banque se propose de faire. Cependant, traditionnellement, des contacts préalables sont pris avec la Commission et, en cas de création d'une nouvelle banque notamment, elle suggère aux intéressés un ou plusieurs noms de réviseurs de banque ${ }^{26}$.

Le statut des réviseurs bancaires connaît ensuite une importante modification, dans le cadre des réformes de régulation bancaire introduites par la loi du 30 juin 1975 (cf. infra). Dans le domaine spécifique du rôle des réviseurs, cette réglementation de 1975 prévoit de nombreux amendements ${ }^{27}$. Les changements finalement adoptés par le gouvernement Tindemans I ne vont certes pas aussi loin que certains des amendements avancés par l'opposition socialiste ${ }^{28}$, mais les modifications effectivement retenues vont dans le même sens. La nomination des réviseurs, qui reste la prérogative de la banque concernée, est désormais officiellement soumise à l'approbation de la Commission bancaire, qui peut également la révoquer. De plus, la Commission bancaire peut fixer le nombre de réviseurs engagés par chaque banque et doit donner son accord à la rémunération prévue. Enfin, le mandat d'un réviseur auprès d'une banque est limité à six années, pour introduire un système de rotation des missions révisorales ${ }^{29}$.

En 1975, le principe fondamental du contrôle réalisé par des agents privés est donc maintenu, mais les pouvoirs de la Commission bancaire dans ce processus sont renforcés. Son droit de regard sur les nominations des réviseurs vient s'ajouter à une nouvelle compétence introduite avec la loi du 30 juin 1975 : désormais, la Commission bancaire peut, dans certains cas bien précis justifiant une telle intervention, procéder à des enquêtes et des expertises directement auprès des banques ${ }^{30}$. Mais cette capacité d'inspection directe, légalement limitée, a un caractère discontinu et n'implique pas la formation de son propre corps d'inspecteurs qui se superposerait à la surveillance exercée par les réviseurs ${ }^{31}$.

Des modifications ultérieures du système révisoral auront lieu en 1980, puis en $1993^{32}$. Dans les années 1980, le contrôle externe sera scindé en deux fonctions distinctes : l'une privée, réalisée par le « commissaire-réviseur » selon la législation sur les sociétés, et l'autre, à vocation publique, effectuée par un « réviseur agréé » au nom de la Commission bancaire. Ce dédoublement du contrôle ne satisfera pas, si bien qu'il sera supprimé dans la loi bancaire du 22 mars 1993. Le contrôle révisoral sera alors à nouveau réuni sous la responsabilité d'une seule entité. En outre, celle-ci pourra désormais prendre la forme d'une société de réviseurs (et non plus uniquement une personne physique), rapprochant

26 Commission bancaire, Rapport annuel, 1973-1974, p. 69.

A. BRUYNEEL, « La loi du 30 juin 1975 », op. cit., p. 655-657.

Les propositions de Joseph Wiard et d'Henri Deruelles demandaient que la Commission bancaire nomme et rémunère les réviseurs elle-même, au lieu des banques. La Commission bancaire et la BNB auraient par ailleurs fait une suggestion similaire dans une note commune (ibidem, p. 655, note 149).

29 Cf. J. LE BRUN, C. LEMPEREUR, La protection de l'épargne publique et la Commission bancaire, Bruxelles, Bruylant, 1979, p. 172-177. Cf. aussi Commission bancaire, Rapport annuel, 1975-1976, p. 35-37.

30 A. BRUYNEEL, « La loi du 30 juin 1975 », op. cit., p. 655-657. H. CousY, « De wet van 30 juni 1975 betreffende het statuut van de banken, de private spaarkassen en bepaalde andere financiële instellingen », Rechtskundig Weekblad, 1976, p. 1397 («Buiten de informatie die de Bankcommissie krijgt via haar revisoren en op grond van de mededelingen welke de banken krachtens artikel 12 (...) moeten verstrekken, kan zij thans ook zelf zich alle inlichtingen doen verstrekken, onderzoeken en expertises verrichten, en, zonder verplaatsing, kennis nemen van elk document van de bank of in het bezit van deze laatste»).

31 Propos du ministre des Finances, le libéral Willy de Clercq, rapportés dans J. LE BRUN, C. LEMPEREUR, La protection de l'épargne publique et la Commission bancaire, op. cit., p. 161.

32 H. DE SMEDT, Regards rétrospectifs sur les origines et l'évolution du rôle et de la fonction des réviseurs agréés et sur la contribution de leur institut au contrôle prudentiel en Belgique, op. cit., p. 49-50. 
ainsi le système belge des standards internationaux où dominent les grandes compagnies d'audit financier - aujourd'hui souvent désignées par l'expression "Big Four » (Deloitte Touche Tohmatsu, Ernst \& Young (EY), Klynveld Peat Marwick Goerdeler (KPMG), PricewaterhouseCoopers).

\subsection{LES RÉVISEURS DE LA BANQUE DE LA SOCIÉTÉ GÉNÉRALE}

Pour terminer ce passage en revue de la gestion par la Commission bancaire de l'activité des réviseurs, prenons un exemple particulier. Qui sont les réviseurs nommés par la plus grande banque de dépôt du pays, à savoir la Banque de la Société générale de Belgique (BSGB) - renommée Société générale de banque (SGB) en 1965, après la fusion avec la Banque d'Anvers et la Société belge de banque -, entre 1936 et 1975 ? Le tableau 1 recense tous les réviseurs nommés par la BSGB, selon la liste dressée par les rapports annuels de la Commission bancaire.

Tableau 1. Réviseurs de la Banque de la Société générale de Belgique/ Société générale de banque (1936-1975)

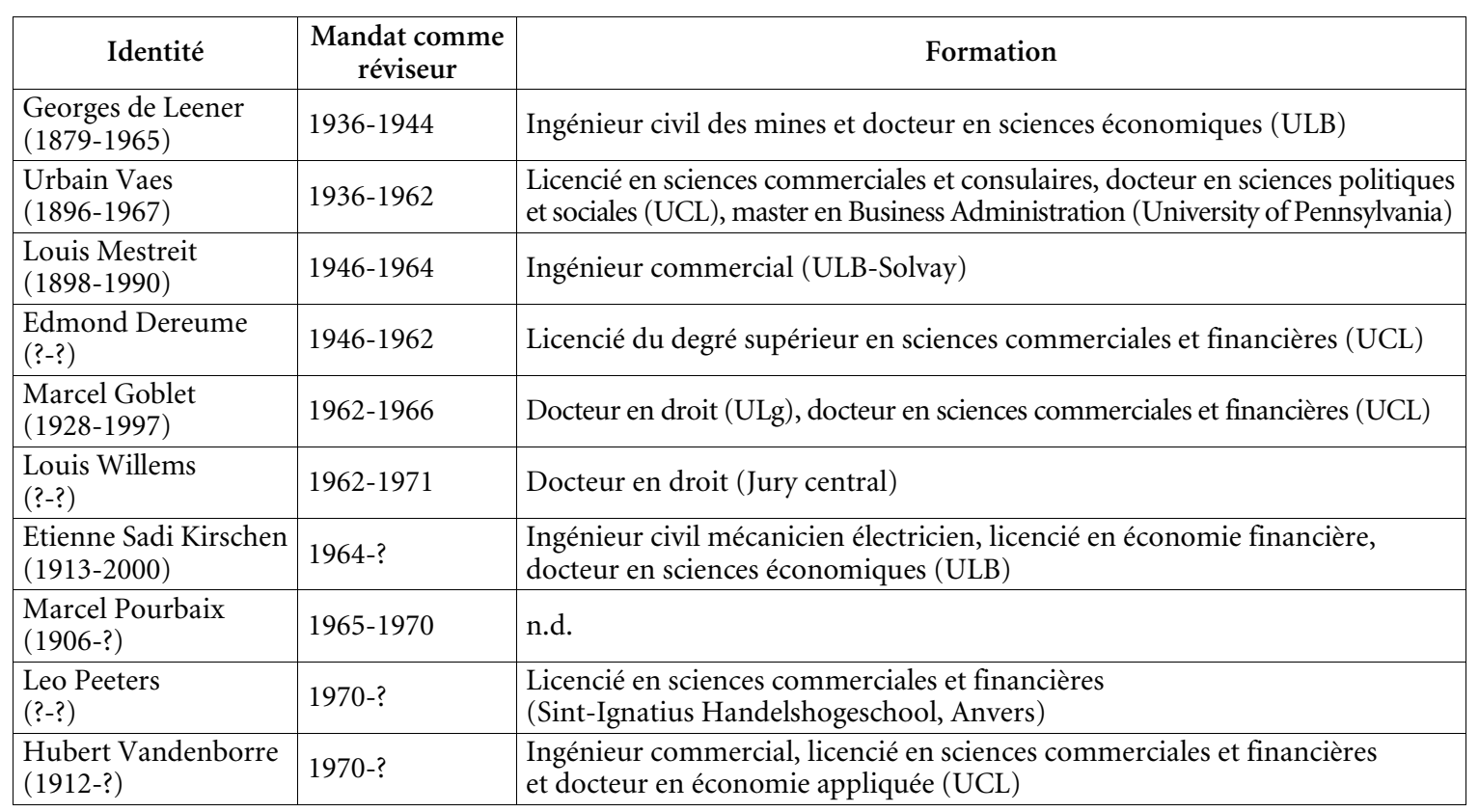

Sources : Rapports annuels de la Commission bancaire pour les années correspondantes ; BNP Paribas Fortis Historical Centre, Fonds Banque de la Société générale de Belgique [BSGB], 984, Organisation du révisorat des banques (1936-1947) ; BNP Paribas Fortis Historical Centre, BSGB, 985, Notes sur les réviseurs.

On constate que, pendant près de quarante ans, seuls dix réviseurs se voient confier un mandat par la plus grande banque belge. Alors que seuls deux réviseurs ont la charge de contrôler la BSGB jusqu'en 1946, un collège de trois réviseurs est nommé à partir de cette date. Leurs mandats sont relativement longs ; ainsi, Urbain Vaes, désigné fin 1935, reste réviseur pendant 26 ans jusqu'à l'atteinte de la limite d'âge en 1962. Leur capital scolaire est très important. Nombre d'entre eux exercent un professorat en parallèle 
à leur fonction de réviseur. Georges de Leener, «libéral convaincu », enseigne les sciences économiques à l'ULB ${ }^{33}$; U. Vaes est professeur d'économie à l'UCL ${ }^{34}$; Étienne Sadi Kirschen est professeur au département d'Économie appliquée de l'ULB ${ }^{35}$; Hubert Vandenborre enseigne également à l'UCL. La banque cherche donc à attirer les réviseurs agréés les plus renommés, ceux dont le prestige scientifique est le plus élevé. Pour d'autres, comme Marcel Goblet, la charge de réviseur de la BSGB représente une première prise de contact prometteuse avec le groupe de la Société générale : il deviendra directeur de la SGB $(1973-1988)^{36}$.

Le choix de réviseurs par la BSGB ne satisfait pas toujours pleinement la Commission bancaire. Les deux premiers réviseurs, G. de Leener et U. Vaes, sont nommés en décembre 1935. Ils remplacent le collège de commissaires qui exerçait jusqu'alors le contrôle voulu par le droit des sociétés ${ }^{37}$. Ils semblent exercer leur rôle dans un esprit qui convient bien aux dirigeants du groupe. Les dirigeants de la Société générale se montrent en revanche moins heureux de la position de la Commission bancaire à l'égard de ses réviseurs. En février 1940, le gouverneur de la Société générale, Alexandre Galopin, écrit à Auguste Mélot, administrateur de la BSGB : «Vous savez combien les deux personnalités qui remplissent ces fonctions [de réviseurs] auprès de notre banque sont hautement qualifiées pour exercer le contrôle prévu par la loi. Nos réviseurs effectuent les tâches qui leur incombent avec toute l'indépendance que la loi exige d'eux et avec une conscience à laquelle je ne puis assez rendre hommage. Malheureusement, l'esprit de la Commission bancaire, à laquelle ils doivent rendre compte de leur mission, est infiniment moins compréhensif et, s'ils cédaient à ses instances, ils seraient amenés à s'immiscer réellement dans des questions qui relèvent de la direction même des affaires bancaires ${ }^{38}$.

Selon ce témoignage, les réviseurs sont placés dans une position délicate. Ils doivent à la fois remplir les tâches de contrôle conférées par la réglementation bancaire et, en même temps, réfréner les velléités de la Commission bancaire cherchant à obtenir des informations supplémentaires. Le renouvellement des réviseurs auprès de la BSGB se déroule également parfois dans une ambiance tendue. En septembre 1943, en prévision du départ de G. de Leener qui atteint la limite d'âge, le président de la BSGB, Willy de Munck, s'entretient avec le président de la Commission bancaire, $M$. Frère. Cette conversation est rapportée dans les termes suivants dans les procès-verbaux de la Commission bancaire : «M. de Munck ne désire pas choisir un réviseur sur la liste actuelle. Il a demandé si la Commission n'agréerait pas comme réviseur un candidat nouveau qui serait proposé par la banque. Devant le refus du président, M. de Munck a déclaré que la banque ne remplacerait probablement pas M. de Leener lors de la prochaine assemblée générale

33 G. DuChENNE, Esquisses d'une Europe nouvelle : l'européisme dans la Belgique de l'entre-deux-guerres (19191939), Bruxelles, Peter Lang, 2008, p. 557.

34 Cf. E. BUYST, H. VANDENBORRE, « 100 jaar toegepaste economische wetenschappen aan de K.U.Leuven », Tijdschrift voor economie en management, volume 43, $\mathrm{n}^{\circ} 4,1998$, p. 513-548.

35 M. Constas, D. Devriese, K. Oosterlinck (dir.), Solvay Business School, 1903-2003, Bruxelles, Archives de l'ULB, 2003, p. 52.

36 G. KuRgan-VAn HentenryK, Gouverner la Générale de Belgique. Essai de biographie collective, Bruxelles, De Boeck Université, 1996, p. 212.

37 Ce collège était composé des personnalités suivantes en octobre 1935, avant le remplacement par G. de Leener et U. Vaes : P. Bregentzer, A. Hayen, G. Henry de Frahan, F. Janssens de Bisthoven, J. Netzer et E. Wibaut.

38 AGR2, Fonds Société générale de Belgique, versement 4, dossiers Galopin, 165, Lettre d'A. Galopin à Auguste Mélot, 20 février 1940. 
et se réserverait de rediscuter la question lorsqu'il y aurait à nouveau un ministre des Finances. M. de Munck estime en effet que la légalité de l'arrêté de novembre 1939 donnant à la Commission le pouvoir de limiter le nombre de réviseurs pourrait être discutée ${ }^{39}$. Tandis que les dirigeants de la grande banque souhaitent obtenir une dérogation, en incitant la Commission bancaire à assermenter un nouveau réviseur "sur mesure", l'autorité de surveillance refuse d'y consentir. La banque met d'ailleurs à exécution ses menaces : elle ne nomme pas immédiatement un remplaçant à G. de Leener. Entre 1944 et 1946, U. Vaes opère comme seul et unique réviseur.

La Commission bancaire cherche également à intervenir pour éviter autant que possible le cumul des mandats de révision auprès de plusieurs sociétés faisant partie d'un même groupe. Il n'est en effet pas rare qu'un réviseur soit désigné par plusieurs banques affiliées. Ainsi, U. Vaes et Louis Mestreit cumulent les charges de réviseurs de la BSGB et de la Banque d'Anvers, un établissement faisant partie du groupe de la Générale en tant que banque patronnée ${ }^{40}$. En janvier 1957, lorsque les dirigeants de la Société générale souhaitent confier à U. Vaes le mandat de réviseur de la société holding SGB, en plus des révisions de la BSGB et de la Banque d'Anvers, la Commission bancaire intervient. $\mathrm{Au}$ cours d'un entretien avec le directeur de la Société générale, Jules Dubois-Pélerin, E. de Barsy fait part de sa «grande perplexité » à l'égard de la candidature d'U. Vaes comme réviseur de la SGB. Il craint que ce cumul de mandats le marque publiquement d'une "inféodation au groupe » ${ }^{41}$. Ces négociations s'insèrent dans le contexte général des négociations autour de l'autonomie bancaire et de la séparation personnelle et financière entre banques de dépôt et holdings industriels (cf. infra).

Relevons encore que les négociations entre une banque et la Commission bancaire, autour de la désignation des réviseurs, se produisent pour d'autres banques que la BSGB. En mai 1952, par exemple, la Kredietbank et la Banque de Bruxelles obtiennent chacune l'ajout à la liste des réviseurs de deux personnalités auxquelles elles souhaitaient respectivement offrir un mandat de révision ${ }^{42}$. En l'occurrence, la Commission bancaire donne son aval et accepte les deux candidatures. Quatre ans plus tard, l'autorité de surveillance se prononce à nouveau sur la problématique générale des réviseurs bancaires. Pour garantir l'indépendance des réviseurs à l'égard du groupe financier contrôlé, elle décide de « faire confiance, au premier degré, aux décisions que l'Institut des réviseurs d'entreprises prend (...) dans l'exercice de sa discipline ${ }^{43}$. Autrement dit, la Commission bancaire s'en remet en grande partie à la régulation interne que la corporation des réviseurs d'entreprises assure.

39 ABNB, Procès-verbal de la Commission bancaire, 28 septembre 1943.

G. VANTHEMSCHE, «La Banque de 1934 à nos jours », in H. VAN DER WEE (dir.), La Générale de Banque, 1822-1997, Bruxelles, Racine, 1997, p. 391.

BNP Paribas Fortis Historical Centre, Archives Jules Dubois-Pélerin, 501, Note d'un entretien avec E. de Barsy, signée J. Dubois-Pélerin, 17 janvier 1957.

42 AGR, CBFA, 153, Procès-verbal de la Commission bancaire, 20 mai 1952, p. 10-11. Il s'agit en l'occurrence de Marcel Loeys (Kredietbank) et de René Clemens (Banque de Bruxelles).

43 AGR, CBFA, 155, Procès-verbal de la Commission bancaire, 8 mai 1956, p. 4. 


\section{LES COEFFICIENTS BANCAIRES ET COEFFICIENTS DE RÉSERVE}

Au moins depuis la mise au point des recommandations du Comité de Bâle sur le contrôle bancaire (en anglais, Basel Committee on Banking Supervision - BCBS), qui aboutit une première fois en 1988, les notions de ratios de fonds propres et de liquidité sont considérées comme des composantes essentielles de la régulation bancaire ${ }^{44}$. De prime abord, pour le profane en particulier, ces mesures prudentielles apparaissent comme des dispositions éminemment techniques, dont la définition et l'application sont l'apanage d'experts et dont les conséquences tangibles semblent éloignées. Dans le cas de la Belgique, l'application au cours des Trente Glorieuses des règles sur les coefficients bancaires met au contraire en exergue des enjeux politiques très concrets. Il n'est d'ailleurs pas étonnant que cet aspect de l'activité de la Commission bancaire soit évoqué dans des études historiques abordant des sujets plus généraux que la surveillance bancaire ${ }^{45}$. Dans le cadre du présent Courrier hebdomadaire, nous n'allons pas entrer dans le détail de la fixation des divers coefficients, mais plutôt analyser la question comme un exemple d'une intervention assez étendue d'une autorité de surveillance bancaire dans la politique économique nationale.

44 Cf., par exemple, C. R. SCHENK, E. MOURLON-DruOL, « Bank Regulation and Supervision », in Y. CASSIS, R. S. Grossman, C. R. SCHENK (dir.), The Oxford Handbook of Banking and Financial History, op. cit., p. 395-419. Sur l'histoire du Comité de Bâle, cf. C. GOODHART, The Basel Committee on Banking Supervision. A History of the Early Years, 1974-1997, Cambridge, Cambridge University Press, 2011.

45 A. P. Timmermans, Les banques en Belgique (1946-1968), Courtrai, Groeninghe, 1969, p. 46-112; H. Houtman-De SMedT, «The Banking System in Belgium through the Centuries », in M. POHL, S. FreITAG (dir.), Handbook on the History of European Banks, Aldershot, Edward Elgar, 1994, p. 47-96; G. VANTHEMSCHE, «La Banque de 1934 à nos jours », op. cit., p. 309-311, 397-399 et 402-405; I. CASSIERS, V. DE Briey, F. Degrave, A.-C. Provost, « Les banques belges face à l'État : une rétrospective (1935-1993) », Revue d'économie financière, volume 48, 1998, p. 125-155; G. KURGAN-VAN HENTENRYK, S. TILMAN, "Les banques locales et régionales en Belgique", in M. LesCure, A. Plessis (dir.), Banques locales et banques régionales en Europe au XX siècle, Paris, Albin Michel, 2004, p. 61-81 ; R. BRION, J.-L. MOREAU, Banque nationale de Belgique, 1939-1971, tome 2: La politique monétaire belge dans une Europe en reconstruction (1944-1958), Bruxelles, Banque nationale de Belgique, 2005, p. 374-376, 421-425 et 482485 ; H. VAN DER WEE, «The Economic Challenge Facing Belgium in the $19^{\text {th }}$ and $20^{\text {th }}$ Centuries », in H. VAN DER Wee, J. Blomme (dir.), The Economic Development of Belgium since 1870, Cheltenham, Edward Elgar, 1997, p. 58 ; E. BuYsT et al., La Banque nationale de Belgique, du franc belge à l'euro. Un siècle et demi d'histoire, Bruxelles, Racine, 2005, p. 173-189 ; I. CASSIERS, P. LEDENT, « Belgian Monetary Policy under Bretton Woods », in M. MÜller, T. Myllyntaus (dir.), Pathbreakers. Small European Countries Responding to Globalisation and Deglobalisation, Berne, Peter Lang, 2008, p. 417 ; P. TILlY, André Oleffe. Un homme d'influence, Bruxelles, Le Cri, 2009, p. 77-78. 


\subsection{L'ANCRAGE JURIDIQUE DES COEFFICIENTS}

Le statut légal de 1935 introduit l'obligation pour les banques de respecter deux ratios entre divers éléments de l'actif et du passif ${ }^{46}$. Le texte définitif de l'arrêté royal du 9 juillet 1935 traite la question des proportions minimales de manière peu précise. La réglementation établit alors uniquement le principe du respect de deux rapports entre les dépôts et les placements et entre les engagements et les fonds propres. Le rapport au Roi précise seulement que les coefficients « doivent être adaptés aux circonstances changeantes et mis en harmonie avec les conditions propres aux différents types de banques $"{ }^{47}$. Autrement dit, les législateurs se contentent d'instituer une disposition relativement floue et laissent le soin à la future Commission bancaire de trancher la délicate question des modalités précises et de la mise en pratique de ces ratios. S'agit-il d'une stratégie délibérée ou d'une simple négligence due à la rapidité d'élaboration de la législation? Il est difficile de trancher définitivement.

Quoi qu'il en soit, cette délégation de la fixation des taux de couverture a pour effet de repousser de plus d'une décennie la prise de décision concrète et l'entrée en vigueur d'une réglementation sur les coefficients bancaires. En effet, ce n'est qu'en janvier 1946, dans des conditions nécessairement très différentes de celles qui ont présidé à l'inscription du principe dans la loi, que la Commission bancaire saisit l'opportunité offerte par l'article 11 de l'arrêté royal du 9 juillet 1935 et édicte un règlement sur les coefficients bancaires. Pendant près de dix ans - dont certes quatre se sont écoulés dans les circonstances très particulières de la Seconde Guerre mondiale et de l'occupation allemande -, les banques belges n'ont de fait été soumises à aucun ratio minimal de liquidité ou de solvabilité.

L'absence de règlement pour mettre en application les principes des deux ratios exprimés dans la législation de 1935 n'est pas réellement justifiée publiquement par la Commission bancaire. En avril 1936, elle avoue attendre l'écoulement d'un «temps d'observation ${ }^{48}$. Dans son premier rapport annuel, datant de la même année, elle signale très pudiquement qu'une intervention dans ce domaine n'est pas nécessaire: "Dans les conditions économiques qui ont prévalu en 1936, la Commission bancaire a préféré mettre en œuvre le principe inscrit dans l'article 11, d'une manière officieuse en usant de son influence et en intervenant dans des cas d'espèce plutôt que par voie réglementaire » ${ }^{49}$.

T. GIDDEY, «Formation et spécificités historiques de la Commission bancaire (1935-1975) », op. cit. Arrêté royal du 9 juillet 1935 sur le contrôle des banques et le régime des émissions de titres et valeurs, Moniteur belge, 10 juillet 1935, rapport au Roi.

$48 \mathrm{ABNB}, \mathrm{O} 303 / 6$, Commission bancaire et $\mathrm{BNB}$, Lettre non signée (probablement F. De Voghel) à E. de Barsy, chef détaché au cabinet du ministre des Finances, 4 avril 1936.

49 Commission bancaire, Rapport annuel, 1936, p. 66. 


\subsection{PREMIÈreS MISES EN GUUVRE DES COEFFICIENTS PAR LA COMMISSION BANCAIRE}

La donne change à la sortie de la Seconde Guerre mondiale. Face à l'endettement public massif hérité des dépenses de guerre, le règlement sur les coefficients bancaires est pour la première fois mis en application en janvier 1946, afin de geler la dette publique à court terme et de permettre à l'État de se financer sans recours au marché monétaire. En effet, pendant le conflit, les banques belges ont trouvé dans l'endettement public une source de placements liquides, pour des ressources qui n'auraient pas trouvé de débouchés dans le secteur privé ${ }^{50}$. En l'occurrence, 78 milliards des 228 milliards de francs belges de dépenses réalisées par l'État durant la guerre ont été couverts par l'emprunt; à la Libération, le portefeuille des fonds publics des banques est dix fois supérieur à celui de $1939^{51}$. En 1944, $84 \%$ du total des crédits bancaires sont accordés à l'État, une proportion record dans l'histoire du pays ${ }^{52}$.

Cet accroissement spectaculaire de la dette à court terme pose de sérieuses difficultés dans la reconversion vers l'économie de paix. Pour le gouvernement et la BNB, il faut avant tout éviter que l'échéance de cette dette massive menace les finances publiques et que les banques remettent sur le marché les emprunts d'État à court terme, ce qui, par effet de création monétaire, relancerait l'inflation. Dans un premier temps, ce défi est résolu par la simple prorogation de l'échéance des certificats de trésorerie souscrits pendant le conflit. Ce régime, moins profitable pour les banques en raison du rendement proportionnellement faible de ces certificats, est maintenu jusqu'en décembre 1945. Dès septembre 1945, les responsables de la Commission bancaire envisagent une solution à cette problématique qui passerait par la fixation de coefficients de structure. Pour son président E. de Barsy, « cette dette doit être considérée comme un résidu incompressible de l'inflation qui s'est produite sous l'occupation. Ce résidu ne peut être absorbé ni par l'impôt, ni par l'emprunt volontaire. Il importe donc à son avis qu'un statut permanent soit donné à cette dette de l'État » ${ }^{53}$. En conséquence, il propose de "constater par un règlement qu'il y a une créance globale permanente des banques sur l'État et que, par conséquent, une fraction de l'actif des banques sera obligatoirement investie en des fonds d'État d'une nature particulière ${ }^{54}$.

S'ensuivent, entre septembre 1945 et janvier 1946, des négociations entre E. de Barsy (Commission bancaire), M. Frère (BNB) et le ministre des Finances, Franz de Voghel, au sujet de ce règlement. Lorsque, en décembre 1945, un avant-projet est soumis aux membres de la Commission bancaire, le représentant du patronat industriel, Karel Steverlynck, exprime des doutes; il se demande si «l'obligation imposée aux banques de posséder toujours un minimum d'effets publics n'aura pas pour effet de réduire leurs

\footnotetext{
I. CASSIERS et al., « Les banques belges face à l'État », op. cit., p. 129.

R. BRION, J.-L. MOREAU, Banque nationale de Belgique, 1939-1971, op. cit., p. 374.

I. CASSIERS et al., «Les banques belges face à l'État », op. cit., p. 129.

ABNB, [fonds non inventorié], Procès-verbal de la Commission bancaire, 25 septembre 1945, p. 3.

ABNB, [fonds non inventorié], Procès-verbal de la Commission bancaire, 25 septembre 1945, p. 4.
} 
possibilités de crédit à l'industrie privée à un moment où celle-ci aura particulièrement besoin de soutien pour assurer la reprise économique dans le pays $\gg{ }^{55}$. E. de Barsy balaie ces doutes, évoquant l'inflation qui résulterait du financement industriel, ainsi qu' « un juste partage entre la satisfaction des besoins de l'État et de ceux de l'économie privée ».

Une semaine plus tard, la même confrontation se reproduit en interne à la Commission bancaire, lorsqu'il s'agit de fixer les ratios précis de couverture. K. Steverlynck et l'avocat catholique Ludovic Moyersoen estiment que les coefficients trop élevés gênent les banques dans l'octroi de crédit à l'économie privée. E. de Barsy leur répond que ces coefficients doivent « être dictés par le souci de fixer un statut convenable à l'endettement permanent de l'État envers les banques » et qu'il s'agit d'éviter « des modifications anarchiques et inadmissibles » de la structure de la dette flottante ${ }^{56}$.

Le 29 janvier 1946, après une consultation de représentants de l'Association belge des banques $(\mathrm{ABB})$, qui obtiennent une réduction de taux de liquidité et de couverture, la Commission bancaire achève la mise au point du premier règlement sur les coefficients bancaires, qui entre en vigueur le 31 mars suivant ${ }^{57}$. Il rend obligatoire le respect de trois ratios ${ }^{58}$. Primo, un coefficient de trésorerie, correspondant à un ratio de liquidité, détermine une proportion entre l'encaisse et les avoirs à vue (les actifs aisément mobilisables) et le passif exigible à court terme (dépôts à court terme). Secundo, un coefficient de solvabilité, correspondant à un ratio de fonds propres, fixe le rapport minimal entre les fonds propres (capital et réserves) et le passif total exigible (fonds de tiers). Ces deux ratios constituent des dispositifs prudentiels relativement courants, destinés à assurer la sécurité et la stabilité des dépôts bancaires. Tertio, un coefficient de couverture impose aux banques que la somme de leur trésorerie (actifs aisément mobilisables) et leurs effets publics (soit les certificats de Trésorerie émis à moyen ou court terme) représente une certaine proportion du passif exigible (les dépôts). Autrement dit, ce dernier ratio, dit de couverture, impose aux banques d'investir une partie de leurs dépôts en certificats du Trésor; il a donc un impact immédiat sur le gel de la dette flottante héritée de la guerre. Ces trois coefficients affectent les établissements bancaires à des degrés divers, puisque la Commission bancaire opère une division en trois catégories, selon la dimension des fonds propres : 7 banques de "grande circulation » (plus de 500 millions), 18 banques de "moyenne circulation" (entre 100 et 500 millions) et 68 banques « régionales et spécialisées » (moins de 100 millions) ${ }^{59}$.

55 ABNB, [fonds non inventorié], Procès-verbal de la Commission bancaire, 11 décembre 1945, p. 2.

ABNB, [fonds non inventorié], Procès-verbal de la Commission bancaire, 18 décembre 1945, p. 4.

Règlement d'exécution du 29 janvier 1946 de l'article 11, \$1, de l'arrêté royal du 9 juillet 1935 sur le contrôle des banques et le régime des émissions de titres et valeurs, Moniteur belge, 10 février 1946.

58 Pour une synthèse sur l'élaboration du règlement de 1946, cf. aussi Commission bancaire 1935-1960, op. cit., p. 94-101.

59 R. Brion, J.-L. Moreau, Banque nationale de Belgique, 1939-1971, op. cit., p. 375. 
Tableau 2. Coefficients bancaires (article 11) de 1946, 1949, 1961 et 1965

\begin{tabular}{|l|c|c|c|}
\multicolumn{1}{c|}{} & \multicolumn{2}{c|}{ Règlement du 29 janvier 1946 } \\
\cline { 2 - 4 } \multicolumn{1}{c|}{} & $\begin{array}{c}\text { Coefficient de trésorerie } \\
\text { (liquidités versus dépôts } \\
\text { à court terme) }\end{array}$ & $\begin{array}{c}\text { Coefficient de solvabilité } \\
\text { (fonds propres versus total } \\
\text { du passif) }\end{array}$ & $\begin{array}{c}\text { Coefficient de couverture } \\
\text { (liquidités et effets publics } \\
\text { versus dépôts à court terme) }\end{array}$ \\
\hline $\begin{array}{l}\text { Banques de grande } \\
\text { circulation }\end{array}$ & $4 \%$ & $5 \%$ & $65 \%$ \\
\hline $\begin{array}{l}\text { Banques de moyenne } \\
\text { circulation }\end{array}$ & $5 \%$ & $7 \%$ & $60 \%$ \\
\hline $\begin{array}{l}\text { Banques régionales ou } \\
\text { spécialisées }\end{array}$ & $6 \%$ & $10 \%$ & $50 \%$ \\
\hline
\end{tabular}

\begin{tabular}{|l|c|c|c|}
\multicolumn{1}{c|}{} & \multicolumn{2}{c}{ Règlement du 11 octobre 1949} \\
\cline { 2 - 4 } \multicolumn{1}{c|}{} & Coefficient de trésorerie & Coefficient de solvabilité & $\begin{array}{c}\text { Coefficient de couverture } \\
\text { assoupli (global-partiel) }\end{array}$ \\
\hline $\begin{array}{l}\text { Banques de grande } \\
\text { circulation }\end{array}$ & $4 \%$ & $5 \%$ & $65 \%-50 \%$ \\
\hline $\begin{array}{l}\text { Banques de moyenne } \\
\text { circulation }\end{array}$ & $4 \%$ & $7 \%$ & $60 \%-40 \%$ \\
\hline Banques régionales & $4 \%$ & $10 \%$ & $50 \%-20 \%$ \\
\hline Banques spécialisées & $4 \%$ & $10 \%$ & $50 \%-30 \%$ \\
\hline
\end{tabular}

\begin{tabular}{|c|c|}
\hline \multicolumn{2}{|c|}{ Règlement du 21 décembre 1961} \\
\hline $\begin{array}{c}\text { Coefficient de solvabilité } \\
\text { Coefficient de réserve } \\
\text { (non permanent, \% des passifs à déposer à la BNB) }\end{array}$ \\
\hline $\begin{array}{c}5 \%, 7 \% \text { ou } 10 \% \text {, selon la taille de l'établissement } \\
\text { (idem que 1946 et } 1949)\end{array}$ & de 0 à $20 \%$, selon le type de passifs \\
\hline
\end{tabular}

Règlement du 5 octobre 1965

\begin{tabular}{|c|c|}
\hline Coefficient de fonds propres & $\begin{array}{c}\text { Coefficient de réserve } \\
\text { (non permanent, \% des passifs à déposer à la BNB) }\end{array}$ \\
\hline De $5 \%$ à $15 \%$, selon la catégorie de risques & de 0 à $20 \%$, selon le type de passifs \\
\hline
\end{tabular}

Sources : Pour 1946 : Règlement d'exécution du 29 janvier 1946 de l'article 11, § 1, de l'arrêté royal du 9 juillet 1935 sur le contrôle des banques et le régime des émissions de titres et valeurs, Moniteur belge, 10 février 1946. Pour 1949: Règlement du 11 octobre 1949 sur les coefficients bancaires, Moniteur belge, 14 octobre 1949. Pour 1961 : Commission bancaire, Rapport annuel, 1961, p. 156-157. Pour 1965 : Commission bancaire, Rapport annuel, 1964, p. XIV-XVI. Cf. aussi A. P. TimMERMANS, Les banques en Belgique (1946-1968), Courtrai, Groeninghe, 1969, p. 46-111.

Le tableau 2 compile l'évolution des différents coefficients bancaires introduits par la Commission bancaire entre 1946 et 1965, en vertu de l'article 11 de l'arrêté royal du 9 juillet 1935. On constate que, en l'espace d'une vingtaine d'années, la réglementation connait de nombreuses modifications. Certains coefficients sont altérés, puis supprimés, parfois au bénéfice d'autres ratios obligatoires. Des trois coefficients initiaux, seul subsiste en 1965 l'équivalent d'un coefficient de fonds propres. Le ratio de liquidité disparaît en 1961. Quant au coefficient de couverture responsable de l'alimentation automatique du Trésor en fonction de la croissance des dépôts, tant décrié par les banques, il est assoupli en 1949, puis transformé par la réforme monétaire de novembre 1957, avant d'être remplacé en 1961 par un coefficient de réserve monétaire.

Avant de revenir succinctement sur les développements qui ont conduit à ces modifications successives, retenons deux éléments. D’une part, le coefficient de liquidité introduit en 1946 place les minimas légaux à des niveaux qui sont déjà atteints par les établissements 
financiers. En effet, pour les grandes banques, le coefficient de trésorerie minimal est fixé à $4 \%$, alors que, en 1942, la liquidité effective des trois plus grandes banques, à savoir la BSGB, la Banque de Bruxelles et la Kredietbank, s'élève respectivement à 13,2 \%, 12,8 \% et $11,4 \%{ }^{60}$. En revanche, en ce qui concerne le coefficient de solvabilité, des adaptations sont nécessaires. En décembre 1946, la Banque de Bruxelles doit procéder à une augmentation de son capital social de 200 à 500 millions de francs belges pour se conformer au règlement ${ }^{61}$. D'autre part, il faut souligner que la réglementation telle qu'elle entre en vigueur en 1946 prend une tournure différente de celle que les législateurs de 1935 avaient conçue. Plus que de simples mesures prudentielles destinées à protéger les dépôts, les coefficients bancaires deviennent alors un instrument pour aménager durablement la dette flottante héritée de la guerre et pour établir un contrôle quantitatif des crédits.

\subsection{L'ÉVOLUTION DES COEFFICIENTS BANCAIRES (1946-1975)}

Ce règlement de 1946 suscite très rapidement des protestations de la part des milieux bancaires, qui y voient un interventionnisme étatique abusif. Presque immédiatement, divers régimes de dérogations sont mis en place par la Commission bancaire pour permettre aux banques de s'adapter progressivement aux nouvelles exigences ${ }^{62}$. Ces dérogations ne sont toutefois pas systématiquement accordées. En novembre 1946, lorsque la Banque de Bruxelles, deuxième établissement du pays, demande un régime d'exception au coefficient de couverture de $65 \%$ par l'assimilation des titres de dette à moyen terme aux effets publics, la Commission bancaire, au terme d'un "débat nourri », finit par refuser. Le président, E. de Barsy, partisan du refus de la dérogation, estime alors que «la couverture doit exercer une triple pression: la première dans le sens de la plus grande modération en matière d'attribution de crédits nouveaux, la seconde dans le sens de la réduction des crédits mobilisables par nature, la troisième dans le sens de l'adoption par les entreprises industrielles et commerciales d'une politique de trésorerie et d'une politique commerciale plus strictes que celles auxquelles la plupart de ces entreprises se sont habituées " ${ }^{63}$. Il obtient finalement gain de cause et s'oppose aux requêtes de MaxLéo Gérard, ancien ministre libéral (qui l'avait désigné chef de cabinet en 1935) et devenu depuis lors président de la Banque de Bruxelles.

La BNB fait aussi preuve de circonspection. Elle craint que le pouvoir réglementaire de la Commission bancaire dans le domaine des coefficients constitue une intrusion dans le domaine de la politique monétaire, chasse gardée de la banque centrale ${ }^{64}$. Les dirigeants de la BNB suggèrent alors, dans le cadre d'une révision de ses statuts, de transférer vers elle la compétence réglementaire sur les coefficients bancaires. Ce projet échoue en 1947 face à l'opposition d'E. de Barsy et à l'arrivée au portefeuille des Finances du social-

60 A. P. Timmermans, Les banques en Belgique (1946-1968), op. cit., p. 48.

J.-M. Moitroux, Une banque dans l'histoire. De la Banque de Bruxelles et de la Banque Lambert à la BBL, Bruxelles, Banque Bruxelles Lambert, 1995, p. 141.

62 Durant les quatre séances de la Commission bancaire qui suivent l'entrée en vigueur du règlement de 1946, 36 des 68 pages des procès-verbaux sont consacrées à l'examen des demandes de dérogation.

63 AGR, CBFA, 155, Procès-verbal de la Commission bancaire, 12 novembre 1946, p. 9-12.

64 R. Brion, J.-L. Moreau, Banque nationale de Belgique, 1939-1971, op. cit., p. 375. 
chrétien Gaston Eyskens, moins à l'écoute des desiderata de la BNB que son prédécesseur F. de Voghel. Parallèlement, fin octobre 1947, les tensions entre la Commission bancaire et la BNB se ravivent lorsque la banque centrale demande à l'autorité de surveillance de contrôler plus strictement le respect des coefficients bancaires ${ }^{65}$. Début 1948, E. de Barsy envisage en effet de céder aux demandes des banques, et en particulier de la Banque de Bruxelles, relayées par l'ABB, en vue d'assouplir le coefficient de couverture ${ }^{66}$. Au printemps 1948, la BNB joue la montre et demande de repousser un tel assouplissement. Lorsque, en novembre 1948, la Commission bancaire soumet un avant-projet d'amendement du règlement sur les coefficients bancaires, les dirigeants de la BNB réagissent à nouveau négativement au « desserrage » envisagé ${ }^{67}$.

Entre décembre 1948 et octobre 1949 se déroulent alors d'intenses négociations entre quatre acteurs principaux, autour de l'assouplissement du coefficient de couverture : la Commission bancaire, la BNB, le Ministère des Finances et l'ABB. La période préélectorale du printemps 1949 repousse la prise de décision définitive au prochain gouvernement. Ce n'est qu'avec la formation du gouvernement Eyskens I (coalition des sociaux-chrétiens et des libéraux), avec le libéral Henri Liebaert au portefeuille des Finances, en août 1949, que l'élaboration de l'amendement reprend. Les divergences entre la Commission bancaire et la BNB persistent cependant. Fin août 1949, E. de Barsy tente un coup de force et cherche à faire passer son projet d'amendement auprès de $\mathrm{H}$. Liebaert, profitant de l'absence du gouverneur de la BNB ${ }^{68}$. Du côté des banquiers, représentés par Robert Hankar, vice-président de la Société belge de banque, et par Jules Bagage, président de la BSGB, la question de l'assouplissement du coefficient est liée au placement d'un emprunt par le gouvernement. Le compte rendu des entretiens entre E. de Barsy et les banquiers révèle que ces derniers « souhaiteraient que les deux questions soient jointes ; c'est-à-dire que le projet de la commission [d'assouplissement du coefficient de couverture] soit sanctionné par le ministre au moment où l'État procédera à l'émission de l'emprunt qu'il envisage $»{ }^{69}$. Ce moyen de pression semble faire effet.

Malgré la réticence du gouverneur de la $\mathrm{BNB}, \mathrm{M}$. Frère, le nouveau règlement sur les coefficients bancaires est approuvé le 11 octobre 1949, la veille du placement prévu de l'emprunt de l'État belge, dont l'intérêt de $4 \%$ est en outre plus de deux points supérieur à celui des certificats de trésorerie $(1,9375 \%)$. En dépit des améliorations nombreuses qu'apporte le nouveau règlement, du point de vue des banquiers, la légalité de toute l'opération est remise en question par les milieux bancaires. Robert Henrion, alors collaborateur du département juridique de la BSGB (qu’il présidera dans les années 1970), fustige dans une note interne le procédé par lequel le gouvernement délègue à une organisation tierce des pouvoirs d'attribution ${ }^{70}$.

Le desserrage des coefficients de 1949 prend la forme d'une subdivision du coefficient de couverture en deux postes, l'un pour les dépôts à vue, l'autre pour les dépôts à terme

\footnotetext{
Ibidem, p. 421.

AGR, CBFA, 155, Procès-verbal de la Commission bancaire, 20 janvier 1948, p. 1-4.

AGR, CBFA, 155, Procès-verbal de la Commission bancaire, 7 décembre 1948, p. 7-9. Cf. aussi R. BRION, J.-L. Moreau, Banque nationale de Belgique, 1939-1971, op. cit., p. 422. 
(cf. Tableau 2). De plus, les effets publics jusqu'à une échéance de cinq ans peuvent désormais être inclus dans le calcul de la couverture ${ }^{71}$. Ces modifications ont pour effet d'améliorer la rentabilité des banques, puisque les papiers à plus long terme désormais autorisés comme effets publics sont plus rémunérateurs que les certificats de trésorerie à court terme ${ }^{72}$. L'objectif plus lointain de l'amendement est de mettre un terme à l'alimentation automatique des finances publiques par l'accroissement des dépôts bancaires. Mais la mise en application de ce nouveau règlement est longtemps repoussée, souvent au grand désarroi de la Commission bancaire, qui regrette l'absence de volonté $\mathrm{du}$ Ministère des Finances à mettre en exécution le nouveau règlement ${ }^{73}$. Plusieurs décisions d'exécution restent dans les faits lettre morte. En 1957, la réduction de 65 à $50 \%$ du taux de couverture en effets publics pour les grandes banques n'est toujours pas réalisée ${ }^{74}$.

Les pourparlers sur la question des coefficients bancaires mettent en évidence des tensions relativement fortes entre la Commission bancaire et les dirigeants des grandes banques de dépôt. En septembre 1948 a lieu une réunion entre le comité central de l'ABB et la Commission bancaire $^{75}$. Les notes internes du président de la BSGB, Fernand Puissant Baeyens, dévoilent l'ambiance dans laquelle se déroule la séance : «M. de Barsy souligne "la pauvreté des arguments" de [la note remise par le comité central de l'ABB]. Le ton est celui que je crois habituel à M. de Barsy, c'est-à-dire celui d'un professeur s'adressant à de mauvais élèves. Atmosphère peu agréable. Déférence excessive de la part des banquiers " ${ }^{76}$. Suite à ce qu'il considère comme un "exorde regrettable» et une «admonestation» de la part du président de la Commission bancaire, F. Puissant Baeyens conteste l'avis d'E. de Barsy et termine son intervention en affirmant qu' ' il est piquant de constater que les représentants de la puissance publique nous demandent de nous incliner devant les principes que nous sommes tous disposés à respecter, mais que la puissance publique elle-même est la première à ne pas respecter ».

Quelques années plus tard, en février 1952, une note adressée par l'ABB au ministre des Finances indique le degré de mécontentement des banquiers : "Il n'y a, à notre connaissance, dans aucun autre pays du monde ayant une structure bancaire analogue à celle de la Belgique, une si grande disproportion entre les moyens que les banques peuvent consacrer au crédit privé et ceux qu'elles sont tenues d'apporter au crédit public. En

71 Cf. R. Brion, J.-L. Moreau, Banque nationale de Belgique, 1939-1971, op. cit., p. 423 ; I. CASSIERS et al., "Les banques belges face à l'État », op. cit., p. 134.

72 A. P. Timmermans, Les banques en Belgique (1946-1968), op. cit., p. 53.

3 Cf., par exemple, AGR, CBFA, 155, Procès-verbaux de la Commission bancaire, 13 mars 1951 et 17 avril 1951.

74 R. Brion, J.-L. Moreau, Banque nationale de Belgique, 1939-1971, op. cit., p. 425 ; A. P. Timmermans, Les banques en Belgique (1946-1968), op. cit., p. 56.

75 BNP Paribas Fortis Historical Centre, BSGB, 984. Sont présents : Eugène de Barsy, Maurice Pitseys, André Oleffe, Henri Neuman (tous Commission bancaire), Robert Hankar (président de l'ABB, Société belge de banque), Philippe Van Isacker (vice-président de l'ABB, Kredietbank), Fernand Puissant Baeyens (BSGB), Max-Léo Gérard (Banque de Bruxelles), Lenoir (Banques moyennes), Lepère (Banques étrangères), Everaert (secrétaire général de l'ABB).

76 BNP Paribas Fortis Historical Centre, BSGB, 984, Note sur la réunion de la délégation du comité central à la Commission bancaire, 9 septembre 1948. 
Belgique même, il n'existe aucune industrie qui soit obligée de céder à l'État, en dessous du prix de revient, les deux tiers de sa production ${ }^{77}$.

En 1956-1957, une nouvelle réforme de la problématique des coefficients bancaires est envisagée $^{78}$. Pour la BNB, il s'agit d'éviter que la croissance des dépôts bancaires alimente automatiquement le Trésor. Plutôt que par l'émission de certificats de trésorerie à court terme, l'augmentation des dépôts pourrait être couverte par des certificats du Fonds des rentes (qui est un établissement public autonome institué en mai 1945, dont l'objectif est d'organiser le marché des fonds publics belges) ${ }^{79}$. Selon ce système prévu, ce serait donc le Fonds des rentes, étroitement lié à la BNB, qui serait compétent pour déterminer le volume de dépôts bancaires à stériliser. Ce projet rencontre l'opposition de la Commission bancaire, qui y voit une immixtion dans ses prérogatives de fixation des coefficients bancaires. Comme en 1949, les négociations qui se déroulent en 1957 sont tendues entre la Commission bancaire et la BNB.

Les désaccords entre les deux institutions trouvent leur équivalent dans les débats internes à la Commission, puisque les représentants de la BNB (Jean Van Nieuwenhuyse en 1949, puis F. de Voghel en 1957) se font les porte-parole de l'opinion défendue par la banque centrale ${ }^{80}$. Alors que les deux institutions s'accordent sur le fond du problème, à savoir une réforme du système mis en place en 1946 dans le sens d'un assouplissement qui soumettrait à nouveau le loyer de l'argent pour les fonds publics à la loi de l'offre et de la demande, elles divergent sur le meilleur moyen d'y parvenir. Toutes deux souhaitent en effet garder la maîtrise sur le volume de la couverture nécessaire.

In fine, en novembre 1957, dans le contexte d'une crise des finances publiques, des arrêtés ministériels relatifs à la réorganisation du marché monétaire sont promulgués ${ }^{81}$. Ceux-ci mettent un terme, statutairement, à l'octroi automatique de crédits au Trésor. Les banques doivent désormais souscrire des certificats du Fonds des rentes, et non plus des certificats du Trésor, pour couvrir leurs passifs ${ }^{82}$. En revanche, le niveau de couverture, à savoir la hauteur des ratios, n'est pas modifié. Parmi les effets collatéraux de cette réforme de 1957, le rendement des placements effectués par les banques à titre de couverture est nettement amélioré. En contrepartie, les grandes banques se sont engagées, par voie protocolaire, à relever leurs taux d'intérêt créditeur sur les dépôts ${ }^{83}$. Cette amélioration des conditions de rémunération chez les banques privées provoque une forte expansion des dépôts à terme, de l'ordre de $28 \%$ de croissance en trois ans, et constitue

77 Note de l'ABB au ministre des Finances, 19 février 1952 (citée dans G. VANTHEMSCHE, « La Banque de 1934 à nos jours ", op. cit., p. 310).

78 Cf. R. Brion, J.-L. Moreau, Banque nationale de Belgique, 1939-1971, op. cit., p. 482-488. Cf. aussi A. P. Timmermans, Les banques en Belgique (1946-1968), op. cit., p. 583-602.

79 Sur la création du Fonds des rentes, qui existe encore aujourd'hui, cf. R. BRION, J.-L. MOREAU, Banque nationale de Belgique, 1939-1971, op. cit., p. 371-373.

Le 16 juillet 1957, le procès-verbal s'achève par cette remarque, qui signale la profondeur des divergences : " [Les thèses d'E. de Barsy et de F. de Voghel] s'affrontent longuement au point que le président, jugeant que la prolongation du débat ne peut guère apporter plus de clarté et que la nécessité de nouvelles réflexions et consultations a été assez mise en évidence, décide que la délibération sera reprise ultérieurement et lève la séance à 19h50 » (AGR, CBFA, 155, Procès-verbal de la Commission bancaire, 16 juillet 1957, p. 14).

81 Arrêtés ministériels du 9 novembre 1957 relatifs à la réorganisation du marché monétaire, Moniteur belge, 12 novembre 1957.

82 A. P. Timmermans, Les banques en Belgique (1946-1968), op. cit., p. 58.

83 AGR, CBFA, 155, Procès-verbal de la Commission bancaire, 19 novembre 1957, p. 1-13. 
donc également un avantage compétitif dans la concurrence avec les institutions publiques de crédit ${ }^{84}$.

C'est un peu plus tard, en 1961, que le régime des coefficients établi en 1946, déjà considérablement assoupli par les réformes de 1949 et 1957, reçoit le coup de grâce. Un nouveau règlement sur les coefficients est promulgué par la Commission bancaire le 21 décembre $1961^{85}$. Il prévoit la suppression définitive des coefficients de couverture, c'est-à-dire le ratio qui imposait une proportion de placements en effets publics relative aux dépôts, et du coefficient de trésorerie, autrement dit le ratio de liquidité. Parmi les trois coefficients initiaux, seul celui sur la solvabilité est alors encore en vigueur. La réforme de 1961 s'explique par la volonté ininterrompue d'abroger le régime des règlements de 1946. Or, les conditions conjoncturelles de la fin de l'année 1961 sont idéales pour mener à bien ce desserrage. La liquidité en quête d'emploi est si importante que le Trésor, même sans contrainte réglementaire, trouverait facilement preneur pour ses émissions ${ }^{86}$.

Dans les faits, la suppression du coefficient de couverture s'opère progressivement, avec ce que l'on pourrait qualifier de mesures d'accompagnement. Tout d'abord, un plancher d'environ 70 milliards de fonds publics est fixé, qui, malgré l'abrogation du coefficient, doit être conservé dans le portefeuille des banques. Ensuite, le coefficient de couverture est remplacé en décembre 1961 par un coefficient de réserve monétaire. Ce nouvel instrument est cependant de nature différente des ratios de 1946 : en effet, il n'est pas permanent, mais peut être exigé par la Commission bancaire, sur proposition de la BNB, de manière temporaire. Il consiste en une réserve monétaire qui doit être déposée auprès de la BNB - sans rapporter d'intérêt - et qui est proportionnelle aux passifs. Le quotient de réserve peut théoriquement varier entre 0 et $20 \%$ selon la longueur des échéances des engagements ${ }^{87}$. Dans les faits, le coefficient de réserve monétaire n'est mis en application qu'une seule fois, entre août 1964 et juillet 1965 , avec un taux de $1 \%{ }^{88}$. Cette intervention, que la BNB juge nécessaire en raison de l'inefficacité de ses recommandations non contraignantes, suscite la désapprobation des milieux bancaires, et notamment de la BSGB, qui considèrent que l'autodiscipline des banques entre 1961 et 1964, en l'absence de tout carcan réglementaire, a fait ses preuves ${ }^{89}$. Les dirigeants bancaires privilégient la voie plus souple des gentlemen's agreements, selon laquelle seules les banques qui enfreignent les accords volontaires seraient pénalisées.

Elles obtiennent d'ailleurs en partie raison, puisque, en juillet 1965, le coefficient de réserve monétaire est abrogé, au profit d'un système volontaire de restriction de crédit ${ }^{90}$. Mais la possibilité pour les autorités publiques de réactiver le recours au coefficient de réserve monétaire reste ouverte, faisant office de moyen de dissuasion. La suppression du

${ }_{85}^{84}$ I. CASSIERS et al., «Les banques belges face à l’État », op. cit., p. 134.

${ }^{3}$ A. P. Timmermans, Les banques en Belgique (1946-1968), op. cit., p. 59-67. Sur la genèse du règlement du 21 décembre 1961 et du coefficient de réserve monétaire, cf. W. Pluym, O. BoEHME, Van de "golden sixties" tot de val van Bretton Woods, Bruxelles, Banque nationale de Belgique, 2005, p. 196-200.

A. P. Timmermans, Les banques en Belgique (1946-1968), op. cit., p. 60.

Ibidem, p. 68.

88 A. BRuYNeEL, "La Commission bancaire belge ", Revue Banque, n³03-305, 1972, p. 22. Cf. aussi Commission bancaire, Rapport annuel, 1964, p. 15-17.

89 G. VANTHEMSCHE, «La Banque de 1934 à nos jours », op. cit., p. 402 ; E. BuYsT et al., La Banque nationale de Belgique, du franc belge à l'euro, op. cit., p. 189.

G. VANTHEMSCHE, «La Banque de 1934 à nos jours », op. cit., p, 403. 
coefficient de couverture en décembre 1961 ne tarde pas à faire effet : elle engendre une réorientation des crédits bancaires vers le secteur privé, plus profitable et plus risqué. Fin 1961, les crédits au secteur privé représentent 58 milliards, contre 90 milliards au secteur public ; fin 1964, ces chiffres s'élèvent respectivement à 104 milliards et 102 milliards ${ }^{91}$.

Enfin, en 1965, le dernier reliquat des coefficients de 1946 subit une réforme importante. Le coefficient de solvabilité est transformé en un coefficient de fonds propres, plus moderne et plus souple. Résumée à grands traits, la refonte opérée dans le règlement du 5 octobre 1965 implique une plus grande pondération des exigences de fonds propres en fonction de l'appréciation des risques, anticipant ainsi un principe généralisé par le Ratio Cooke recommandé dans les années 1980 par le Comité de Bâle sur le contrôle bancaire $^{92}$. Les banques sont donc classées en onze catégories distinctes, selon l'évaluation des risques pris et la nature des actifs, ce classement étant mis à jour annuellement ${ }^{93}$. Dans ce système, les crédits aux pouvoirs publics sont exempts de risques, tandis que les effets non réescomptables, par exemple, entrent dans une catégorie de risques élevés. Le niveau de fonds propres exigé varie entre 5 et $15 \%$ selon les établissements. Avec ce régime, une banque peut donc répondre au coefficient de fonds propres de deux manières : soit du côté du passif, en opérant une augmentation de capital ou des réserves, soit du côté de l'actif, en agissant sur les choix de placement.

S'il est vrai que le nouveau règlement n'implique pas une augmentation globale des fonds propres, puisque le montant total exigé est sensiblement identique à celui requis par le coefficient de solvabilité (17,37 milliards, contre 17,5 milliards), la répartition de ces fonds propres est modifiée selon la politique suivie par chacune des banques ${ }^{94}$. Le règlement sur les fonds propres de 1965 provoque d'ailleurs, indirectement, un encouragement des crédits au secteur public ${ }^{95}$. Pour les banques, la pondération nulle en risque des effets publics représente une incitation à investir dans les crédits publics sans devoir compenser cette expansion par des augmentations de capital. En ce sens, le coefficient de fonds propres de 1965, par ses effets incitatifs vers les crédits au secteur public, constitue une forme de compensation à la suppression du coefficient de couverture en 1961. Une note interne du service des études de la BNB confirme cette hypothèse : la réforme du coefficient de solvabilité en ratio de fonds propres est devenue plus nécessaire depuis la disparition des deux autres coefficients (de trésorerie et de couverture) en $1961^{96}$.

Entre 1969 et 1975, interviennent encore un certain nombre de modifications dans le régime des coefficients bancaires, que nous n'évoquerons ici que sommairement. En mai 1969, la Commission bancaire promulgue, pour une durée limitée à une année, un règlement instituant un coefficient de remploi. Ce texte impose aux banques de « réorienter progressivement leur structure vers une meilleure proportion des actifs

91 A. P. Timmermans, Les banques en Belgique (1946-1968), op. cit., p. 79.

92 L'arrêté de la Commission bancaire instituant un coefficient de fonds propres du 5 octobre 1965 est reproduit en annexe de Commission bancaire, Rapport annuel, 1964, p. XIV-XVI.

93 Pour des données sur le nombre de banques faisant partie des différentes catégories de risques entre 1965 et 1968, cf. A. P. Timmermans, Les banques en Belgique (1946-1968), op. cit., p. 92-93.

Ibidem, p. 93.

95 I. CASSIERS et al., «Les banques belges face à l'État », op. cit., p. 140.

$\mathrm{ABNB}, \mathrm{B} 718 / 5$, « Note sur le coefficient de fonds propres institué par l'arrêté de la Commission bancaire du 5 octobre 1965 » par A. Verplaetse et G. Noppen, 7 janvier 1966. 
aisément négociables par rapport aux passifs exigibles à court terme ${ }^{97}$. En clair, il s'agit d'une mesure contraignante destinée à favoriser les placements dans les fonds publics ${ }^{98}$. Une fois expiré en juin 1970, ce règlement est remplacé par des gentlemen's agreements volontaires pour stériliser une partie des dépôts bancaires auprès de la BNB et contribuer ainsi à la lutte contre l'inflation. En juin 1972, le règlement sur les fonds propres connaît une révision. La Commission bancaire introduit alors une double pondération des exigences : l'une relative à l'estimation des risques parmi les actifs, l'autre liée au total des immobilisations d'une banque et de ses filiales ${ }^{99}$. Cet assouplissement est salué par les milieux bancaires; les administrateurs de la BSGB approuvent « un coefficient d'ébéniste remplaçant l'ancien coefficient de charpentier $"{ }^{100}$. Enfin, par la loi du 28 décembre 1973, qui confirme en fait une évolution amorcée en 1967, intervient un changement dans la répartition des compétences entre la Commission bancaire et la $\mathrm{BNB}$ dans le domaine des coefficients ${ }^{101}$. La BNB obtient le pouvoir réglementaire en ce qui concerne les coefficients touchant à la politique monétaire, et en particulier le droit d'initiative pour des réformes. La Commission bancaire demeure responsable des coefficients à visée prudentielle, en particulier sur les fonds propres ${ }^{102}$. Cette nouvelle délimitation des prérogatives est confirmée dans la loi du 30 juin 1975, qui modernise la formulation de l'article 11 de l'arrêté royal du 9 juillet 1935. Dans sa nouvelle mouture, la réglementation autorise également la Commission bancaire à introduire un coefficient sur les avoirs en devises à terme, ainsi qu'à calculer les exigences en tenant compte des bilans consolidés par groupe et de la concentration des risques sur un seul débiteur important ${ }^{103}$.

\subsection{LES COEFFICIENTS BANCAIRES : UN BILAN}

Au terme de ce passage en revue de l'évolution des coefficients bancaires entre 1945 et 1975, il faut souligner que cette problématique constitue alors un enjeu majeur pour la Commission bancaire. De fait, la détermination des coefficients, ignorée pendant les dix premières années d'existence de l'autorité de surveillance, représente pour celle-ci un précieux outil de contrainte capable d'influencer directement la politique de crédits des banques. Alors que la régulation de 1935 est souvent laconique quand il s'agit de préciser les moyens par lesquels la Commission bancaire doit mettre en œuvre son

97 Commission bancaire, Rapport annuel, 1968-1969, p. 19 (le texte du règlement figure en annexe : ibidem, p. 204-206).

98 Pour un exemple de mise en application du coefficient de remploi, cf. la note du département des études de la BNB, qui s'interroge sur la légalité de la diminution des effets publics chez les grandes banques - en particulier la Banque de Bruxelles - en juillet 1969 (ABNB, B672/31, Note strictement confidentielle par G. Defrance, 2 octobre 1969).

99 Sur le coefficient de fonds propres de 1972, cf. J. LE BRUN, C. LEMPEREUR, La protection de l'épargne publique et la Commission bancaire, op. cit., p. 139-144; G. VANTHEMSCHE, «La Banque de 1934 à nos jours ", op. cit., p. 398.

100 Procès-verbal du conseil d'administration de la BSGB, 24 septembre 1974 (cité par G. VANTHEMSCHE, "La Banque de 1934 à nos jours", op. cit., p. 405).

101 W. Pluym, O. Boenme, Van de "golden sixties" tot de val van Bretton Woods, op. cit., p. 201-202.

102 J. Le Brun, C. Lempereur, La protection de l'épargne publique et la Commission bancaire, op. cit., p. 136.

103 A. BRUYNEEL, « La loi du 30 juin $1975 »$, op. cit., p. 658. 
action - privilégiant ainsi une approche de consultation et de recommandation -, l'arme des ratios bancaires est au contraire conçue comme un dispositif contraignant.

Dans les faits, les coefficients de structure mis en place en 1946 fonctionnent davantage comme des mesures visant à stabiliser un endettement public massif que comme des prescriptions prudentielles de nature à garantir la sécurité des dépôts. Ils sont progressivement assouplis, en plusieurs étapes donnant invariablement lieu à d'intenses négociations, en 1949, 1957, 1961, puis en 1965. Au milieu des années 1970, seul un ratio de fonds propres, qui est conçu dans une phase d'européanisation et qui est davantage en conformité avec les standards internationaux, succède aux divers coefficients de 1946. Mais jusqu'alors, l'instrument des coefficients bancaires a transformé la Commission bancaire en un acteur essentiel dans divers domaines qui dépassent la simple surveillance bancaire : politique monétaire, stabilisation des finances publiques, orientation des crédits bancaires. Cette position influente non seulement suscite des tensions avec la BNB, qui $\mathrm{y}$ voit une intrusion dans sa sphère de compétence, mais également nourrit les critiques des administrés, à savoir les banques de dépôt.

Reste à savoir quel est l'impact de ces diverses mesures sur les performances du secteur bancaire belge pendant la période envisagée. Cette question dépasse largement notre propos. Contentons-nous de mentionner l'analyse de l'économiste Isabelle Cassiers à ce sujet. Selon celle-ci, les contraintes réglementaires favorisent certes alors une orientation privilégiée des crédits bancaires vers le secteur public (à la fin des années 1950, les prêts bancaires aux entreprises et aux particuliers ne représentent que $36 \%$ des dépôts en Belgique, contre $43 \%$ au Royaume-Uni, $72 \%$ en Allemagne ou $87 \%$ en France) ${ }^{104}$, mais cela ne signifie pas pour autant qu'il faille imputer aux seuls coefficients la responsabilité d'une croissance économique comparativement plus lente durant la première période de l'après-guerre. Pour I. Cassiers, «l'hypothèse selon laquelle les coefficients bancaires auraient (...) pour effet de réduire les capacités de crédit au secteur privé des banques et [freineraient par là] l'investissement et la croissance économique semble donc sujette à caution $"{ }^{105}$. Selon cette interprétation, les structures bancaires héritées de la crise et de la guerre joueraient un rôle plus important que l'environnement réglementaire.

104 I. CASSIERS, P. LEDENT, « Belgian Monetary Policy under Bretton Woods », op. cit., p. 417.

105 I. CASsiers et al., «Les banques belges face à l’État », op. cit., p. 136. 


\section{L'APPLICATION DE L'AUTONOMIE BANCAIRE ET LES MESURES SUR LA SCISSION}

À côté de la problématique des coefficients bancaires, les questions relatives à ce qui sera désigné par l'expression "autonomie de la fonction bancaire » constituent le second dossier très sensible qui occupe la Commission bancaire entre 1945 et 1975. Pour le dire rapidement, il s'agit de la façon dont l'autorité de surveillance cherche à traduire dans les faits le principe de séparation entre les banques de dépôt et les holdings (ou sociétés à portefeuille) auxquels elles sont liées. Cette scission doit se traduire par une double indépendance, en ce qui concerne à la fois le personnel dirigeant (le régime des incompatibilités) et une autonomie financière, à savoir un actionnariat principal indépendant.

\subsection{L'AUTONOMIE BANCAIRE DANS LA RÉGLEMENTATION DES ANNÉES 1930 ET LES DIFFICULTÉS INITIALES DE MISE EN GEUVRE PAR LA COMMISSION BANCAIRE}

Du point de vue légal, ces principes, issus des réformes de 1934-1935, trouvent leur expression dans les articles 14 et 16 de l'arrêté royal du 9 juillet 1935. Ces dispositions stipulent que les banques de dépôt ne peuvent pas détenir des participations dans les sociétés commerciales ou industrielles (article 14) et que les dirigeants des banques de dépôt ne sont pas autorisés à prendre part à la gestion des sociétés commerciales ou industrielles (article 16). Cette double interdiction, draconienne en apparence, se révèle très difficile à mettre à exécution dans la pratique. En effet, comme le reconnaîtra plus tard la Commission bancaire, la réglementation de 1935 présente une lacune béante ${ }^{106}$. Si une participation commerciale est bien interdite pour une banque de dépôt, rien n'empêche en revanche un holding de prendre un intérêt déterminant dans une banque. L'absence de cette interdiction réciproque s'explique essentiellement par le fait que l'arrêté royal du 9 juillet 1935 s'applique uniquement aux banques et que les sociétés financières sont, sur la demande expresse des milieux bancaires, exclues de tout contrôle. Il n'en reste pas moins que cette omission va à l'encontre de l'esprit de la législation.

\footnotetext{
106 Commission bancaire 1935-1960, op. cit., p. 81.
} 
Après une phase initiale d'adaptation, la Commission bancaire s'attelle, dans l'après-guerre, à réaliser les objectifs de l'autonomie de la fonction bancaire de façon plus vigoureuse. Ces efforts aboutissent à la signature, en 1960 puis en 1974, de deux protocoles avec les deux principaux groupes concernés : d'une part, la Société générale de Belgique et sa banque, la BSGB, et, d'autre part, la Brufina et sa banque, la Banque de Bruxelles.

Le dossier de l'« autonomie bancaire » est particulièrement sensible pour la Commission bancaire, non seulement car il met en jeu des intérêts personnels impliquant les groupes économiques les plus puissants du pays, mais aussi parce que cette question est parfois reprise à l'agenda politique, comme en 1946 lorsqu'une intervention légale réduisant la participation des sociétés holdings à un quart du capital de leur filiale bancaire est envisagée ${ }^{107}$. En outre, il ne s'agit pas d'un conflit purement juridique autour de la mise en application de normes. Pour la Commission bancaire, il s'agit aussi de mettre en œuvre le principe qui sous-tend la scission et de garantir que les entreprises bancaires développent leurs activités, et notamment l'octroi de crédits, sans considérations étrangères à la technique bancaire, qui pourraient favoriser les intérêts d'un actionnaire dominant. C'est ce développement que les lignes suivantes ont pour but de baliser plus précisément.

Pour comprendre cette problématique, il est nécessaire de rappeler brièvement les conditions dans lesquelles a été mise en œuvre la séparation entre banques et holdings en 1934-1935. Fin 1934, à la suite de l'entrée en vigueur de l'arrêté royal du 22 août 1934, la scission est réalisée par la constitution d'une nouvelle société, qui reprend les activités de banque de dépôt du holding dont elle est issue. Dans le cas du premier groupe du pays, la Société générale de Belgique ne subit aucune modification; elle crée simplement une société filiale, dénommée BSGB, en décembre $1934^{108}$. Dans le cas de la Banque de Bruxelles, la transformation est, sur le papier, légèrement différente. D'abord, l'ancien holding Banque de Bruxelles est rebaptisé "Société de Bruxelles pour la finance et l'industrie » (Brufina); il gère toujours le portefeuille d'investissement. Puis, une nouvelle société est créée qui reprend la raison sociale «Banque de Bruxelles » et les activités bancaires, tout en étant détenue à $100 \%$ par la Brufina ${ }^{109}$. Dans les deux cas, la restructuration opérée se limite à une scission de façade : l'actionnariat des nouvelles entités provient exclusivement des sociétés financières d'origine, qui délèguent également de nombreux représentants dans les conseils d'administration de leurs filiales bancaires ${ }^{110}$.

Cet état de fait suscite, dès 1936, des critiques de la part de la Commission bancaire. Elle écrit dans son premier rapport annuel : « La scission de la plupart des anciennes banques mixtes a été réalisée par la création d'une banque, dont le capital est détenu en totalité ou pour la majeure partie par une société financière très souvent issue elle-même de la scission. La situation qui est ainsi obtenue n'atteint pas le but poursuivi par la législation nouvelle. Dès lors, il convient d'examiner dans chaque cas le processus qui devrait être mis en ouvre pour changer cet état de choses le plus rapidement possible. En attendant que cela puisse être fait, il convient de veiller spécialement à ce que, malgré cette situation

107 G. VANTHEMSCHE, «La Banque de 1934 à nos jours », op. cit., p. 312.

108 Ibidem, p. 296. Pour un récit détaillé sur la naissance de la BSGB, cf. ibidem, p. 296-304 ; G. VANTHEMSCHE, « De politieke en economische context van de Belgische bankwetgevingen van 1934 en 1935 », Revue de la banque, volume 8-9, 1980, p. 31-50.

109 J.-M. MoITroux, Une banque dans l'histoire, op. cit., p. 100.

110 Dans le cas de la BSGB, sept représentants de la société financière siègent au conseil d'administration (G. KuRGAN-VAN HeNTENRYK, Gouverner la Générale de Belgique, op. cit., p. 171). 
particulière et provisoire, la gestion de la banque soit assurée d'une manière complètement indépendante par rapport à celle de la société financière " ${ }^{111}$.

Ces récriminations publiques - les rapports annuels étant publiés - se manifestent également dans la documentation interne de la Commission bancaire. Dans un courrier qu'il adresse à Louis-Jean Mahieu, l'un des membres de la Commission bancaire, en juin 1936, le président G. Janssen rappelle que la situation issue de la scission n'atteint pas le but poursuivi et estime qu'il s'agit alors de surveiller en particulier la gestion indépendante des banques et d'examiner si les crédits accordés aux sociétés financières ne sont pas contraires aux dispositions légales ${ }^{112}$. Un an plus tard, dans le rapport annuel pour 1937, le bilan est toujours décevant : « Il faut bien constater que, dans l'état actuel de la législation, rien n'empêche que des banques tombent directement ou indirectement sous le contrôle de groupes financiers ou industriels qui pourraient se trouver ainsi en mesure de leur imposer une politique de nature à servir leur propre intérêt au détriment de celui des déposants ${ }^{113}$.

Durant une première phase de l'existence de la Commission bancaire, entre 1935 et 1954, l'essentiel de son action sur la question de l'autonomie bancaire porte sur deux volets.

D'une part, elle est sollicitée par les banques pour donner son accord sur de nombreuses requêtes de dérogations à une situation d'incompatibilité. En effet, selon la législation de 1935, un administrateur de banque ne peut conserver qu'un seul mandat dans une société commerciale ou industrielle (article 16). Pour un établissement comme la BSGB, c'est une liste longue de 9 pages énumérant tous les mandats d'administrateurs de ses propres dirigeants qui est envoyée à la Commission bancaire ${ }^{114}$. Dans l'ensemble, ces régimes dérogatoires sont accordés facilement par la Commission bancaire, qui y voit un moyen "de faire entendre la voix de la "raison bancaire" dans les concerts où s'élabore la politique industrielle et financière $"{ }^{115}$. En dépit de cette politique d'octroi de dérogations généreuse, la simple obligation de formuler les demandes d'exception et de transmettre de manière transparente l'ensemble des mandats du personnel dirigeant à un organisme étatique - une transmission parfois suivie d'une enquête sur les liens personnels - confère à la Commission bancaire un capital d'information à l'égard de ses administrés importants. De plus, cela nourrit les ressentiments des banquiers à l'égard d'une législation jugée trop intrusive ${ }^{116}$.

D'autre part, dès 1941, l'autorité de surveillance fait pression sur les grandes banques, par l'intermédiaire des réviseurs, pour obtenir une réduction des participations des holdings industriels dans le capital bancaire. Toute cette problématique ne concerne alors que les grands établissements. Dans une note interne, le secrétaire de la Commission bancaire, F. de Voghel, précise que l'article 14, qui interdit les participations commerciales et industrielles chez les banques, "n'a visé, en définitive, que quelques banques mixtes

\footnotetext{
Commission bancaire, Rapport annuel, 1936, p. 33.

ABNB, J327/12, Lettre de G. Janssen à L.-J. Mahieu, 29 juin 1936.

Commission bancaire, Rapport annuel, 1937, p. 33.

114 Cette liste est conservée dans BNP Paribas Fortis Historical Centre, BSGB, 985, «Incompatibilités », 31 juillet 1936.

115 Commission bancaire, Rapport annuel, 1955-1956, p. 22.

116 Cf. G. VANTHEMSCHE, « La Banque de 1934 à nos jours », op. cit., p. 307.
} 
importantes, une vingtaine au plus, qui ont dû opérer leur scission ${ }^{117}$. Cette action discrète sur les grands groupes financiers conduit à des résultats mitigés. En 1943, la Commission bancaire se réjouit tout de même « d'améliorations importantes » dans la situation d'indépendance des banques ${ }^{118}$. Nous ne disposons malheureusement pas de données permettant de quantifier ces « améliorations ». Comme le montre le graphique 2, élaboré à partir des chiffres publiés par l'historien Guy Vanthemsche, ce désengagement des holdings dans le capital bancaire ne touche pas la Société générale : entre 1935 et 1945, le pourcentage d'actions de la BSGB aux mains de la Société générale ne diminue pas, mais se maintient à hauteur de $50 \%{ }^{119}$.

Graphique 2. Participation de la Société générale de Belgique au capital de la Banque de la Société générale de Belgique (puis Générale de Banque) (1935-1975)

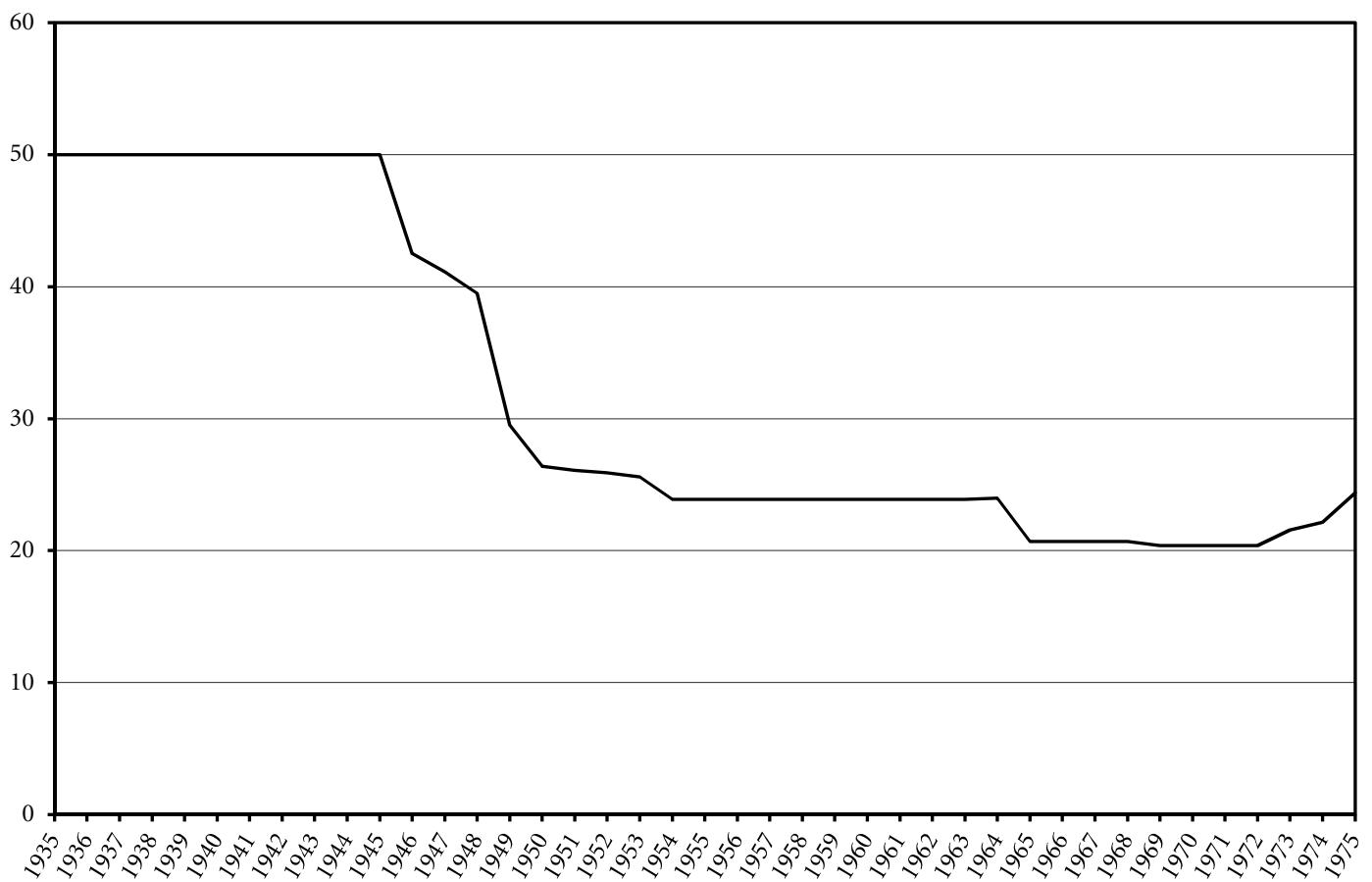

Source: G. VANTHEMSCHE, «La Banque de 1934 à nos jours », in H. VAN DER WEE (dir.), La Générale de Banque, 1822-1997, Bruxelles, Racine, 1997, p. 312 et 406.

Remarque : À partir de 1965, Générale de Banque.

117 ABNB, R589/4, Procès-verbal de la Commission bancaire, 23 avril 1941, Annexe, Note de F. de Voghel, p. 5. Pour un exemple d'une autre scission comptable opérée fin décembre 1934, qui ne concerne ni la Société générale ni la Banque de Bruxelles, cf. P.-F. SMETS, Lambert: une aventure bancaire et financière, 1831-1975, Bruxelles, Racine, 2012, p. 115-118.

118 Commission bancaire, Rapport annuel, 1943, p. 11.

119 G. VANTHEMSCHE, "La Banque de 1934 à nos jours », op. cit., p. 302 et 312. Il est à souligner que, lors de la fondation de la BSGB, les $50 \%$ restants sont répartis entre les actionnaires des anciennes banques patronnées qui sont avalées par la BSGB. Or la Société générale est elle-même actionnaire des banques patronnées. Sa participation réelle dépasse donc $50 \%$. 


\subsection{L'AFFAIRE BRUFINA ET L'AUTONOMIE BANCAIRE DANS LES ANNÉES 1950}

Alors que, dans l'immédiat après-guerre, cette question fait parfois l'objet de revendications politiques, ce n'est qu'à partir du milieu des années 1950, sous l'influence d'événements singuliers qui affectent essentiellement la Banque de Bruxelles, que la Commission bancaire reprend plus activement le dossier de l'autonomie bancaire.

Si l'ensemble des historiens qui évoquent l'«affaire Brufina » situent le point de départ de celle-ci en novembre $1954^{120}$, une première escarmouche a déjà lieu au printemps 1947. Le président de la Commission bancaire, E. de Barsy, signale alors à ses collègues que le président de la société holding Brufina, Paul de Launoit, a l'intention de confier à son fils Paul-Marie une fonction dirigeante dans la Banque de Bruxelles ${ }^{121}$. L'opposition de la Commission bancaire, dénuée de tout support légal, semble suffire à faire renoncer P. de Launoit à son projet. Mais le débat est relancé six ans plus tard. Le 2 novembre 1954, E. de Barsy fait part à ses collègues de la Commission bancaire de son inquiétude face aux déclarations que P. de Launoit a faites lors de l'assemblée générale de la Brufina, qui signalent un conflit ouvert entre la Banque de Bruxelles et le groupe autour de la mise en liquidation d'une société ${ }^{122}$. Ces frictions semblent indiquer que la société à portefeuille cherche à influencer plus étroitement sa banque de dépôt. En plus d'une lettre à la Banque de Bruxelles, la Commission bancaire intervient alors officieusement, sous la forme d'un entretien informel entre E. de Barsy et P. de Launoit, au cours duquel le premier reproche au second les « coups de butoir [sic] que son attitude porte à la construction délicate et nuancée qui s'est établie depuis 1935 en ce qui concerne les rapports entre les banques et les sociétés financières " ${ }^{123}$. La Commission bancaire en reste alors au stade des réprimandes.

En 1956, l'affaire rebondit. La Commission bancaire est à nouveau appelée à intervenir pour protéger l'indépendance de la Banque de Bruxelles et de son président, Louis Camu. La Brufina aurait en effet l'intention de nommer l'ancien Premier ministre Paul Van Zeeland au conseil d'administration et au conseil de direction de la Banque de Bruxelles, dans le but d'assurer la liaison avec la Brufina ${ }^{124}$. Ce projet ne reçoit pas l'approbation de la Commission bancaire, qui y voit un "grand pas en arrière » dans l'affirmation de l'indépendance de la banque, en raison des liens étroits entre P. Van Zeeland et P. de Launoit. En mai 1956, la gestion du dossier s'élargit au ministre des Finances $\mathrm{H}$. Liebaert et à la BNB, qui envisagent une mission de conciliation pour désamorcer le conflit ${ }^{125}$. De difficiles négociations ont lieu pendant l'été $1956{ }^{126}$. Alors

120 Ibidem, p. 315-317 ; R. BRION, J.-L. MOREAU, La Société générale de Belgique, 1822-1997, Anvers, Fonds Mercator, 1998, p. 417 ; R. BRION, J.-L. MOREAU, Banque nationale de Belgique, 1939-1971, op. cit., p. 499 ; P. Tilly, André Oleffe, op. cit., p. 90-91.

121 AGR, CBFA, 148, Procès-verbaux de la Commission bancaire, 15 avril 1947, 13 mai 1947 et $1^{\text {er }}$ juillet 1947. Dans Commission bancaire, Rapport annuel, 1946-1947, p. 27, l'affaire est évoquée sans que soit citée nommément la Banque de Bruxelles.

122 AGR, CBFA, 155, Procès-verbal de la Commission bancaire, 2 novembre 1954.

123 AGR, CBFA, 155, Procès-verbal de la Commission bancaire, 16 novembre 1954, p. 2.

124 AGR, CBFA, 155, Procès-verbal de la Commission bancaire, 17 janvier 1954, p. 8. Cf. également V. Dujardin, M. Dumoulin, Paul Van Zeeland 1893-1973, Bruxelles, Racine, 1997, p. 236-237.

125 R. Brion, J.-L. Moreau, Banque nationale de Belgique, 1939-1971, op. cit., p. 499. 
que seul le groupe de la Brufina était dans le collimateur de la Commission bancaire, les pourparlers s'étendent au groupe de la Société générale. E. de Barsy voudrait inciter la Société générale à diminuer sa participation dans sa filiale bancaire pour pouvoir faire pression sur la Brufina.

Le contexte politique est particulièrement tendu pendant l'été 1956. Le syndicat socialiste, la Fédération générale du travail de Belgique (FGTB), fait en effet pression pour obtenir un contrôle des holdings ${ }^{127}$. Sous l'impulsion du syndicaliste André Renard, des « réformes de structure ", à savoir une forme de contrôle des entreprises avec participation accrue des salariés - dérivée du planisme des années 1930 -, sont revendiquées ${ }^{128}$. Les banquiers, quant à eux, sont bien conscients de la menace que représentent les revendications syndicales, qu'ils résument grossièrement de la manière suivante. Dans une note interne, le directeur de la Société générale, J. Dubois-Pélerin, singe les reproches de la FGTB en évoquant «la féodalité financière - les 212 familles - [qui] possède un pouvoir incontrôlé sur une grande partie de l'économie belge et coloniale. Elle se sert de ce pouvoir incontrôlé pour orienter l'économie belge et coloniale dans une voie peu sociale. Tout en se créant de scandaleuses prébendes » ${ }^{129}$. La stratégie à adopter pour contrer l'« atmosphère démagogique » consiste à contester scientifiquement la thèse syndicale par l'intermédiaire d'un "milieu extérieur non suspect» (J. Dubois-Pélerin songe à mandater l'Institut de recherches économiques et sociales de l'UCL). Dans ce climat, la Commission bancaire cherche à faire pression sur les banques pour obtenir des concessions et, en l'occurrence, une plus forte indépendance des banques de dépôt à l'égard des sociétés mères, c'est-à-dire des changements beaucoup moins radicaux que ceux revendiqués par la FGTB.

Plus précisément, E. de Barsy adopte une stratégie qui consiste à convaincre la Société générale de faire le premier pas dans ce sens, pour «donner l'exemple» et forcer la Brufina à la suivre dans la même voie. La réaction des dirigeants de la Société générale est dans un premier temps plutôt circonspecte. J. Dubois-Pélerin réplique à E. de Barsy : «C'est avec un affreux serrement de cœur que j'envisagerais l'idée d'abandonner notre participation en [BSGB] qui est un morceau de nous-mêmes, une fille aînée particulièrement chère (...). C'est nous demander d'envisager un harakiri particulièrement douloureux, à nous qui - la Commission bancaire l'affirme - n'avons rien à nous reprocher ${ }^{130}$.

Mais E. de Barsy poursuit son opération et maintient une forte pression sur les dirigeants de la Société générale. Il utilise plus précisément deux moyens de contrainte. D’une part, il négocie le contenu du prochain rapport annuel de la Commission bancaire, qui rendra publiques les difficultés auxquelles elle fait face dans le domaine de l'autonomie bancaire. D'autre part, E. de Barsy présente un retrait - complet ou partiel, avec le maintien d'une participation minime - du holding de la filiale bancaire comme un geste politique, qui

126 Le problème de l'autonomie bancaire figure à douze reprises dans l'ordre du jour des séances de la Commission bancaire entre janvier et octobre 1956.

P. Tilly, André Oleffe, op. cit., p. 93.

128 Cf. P. Tilly, André Renard, Bruxelles, Le Cri, 2005.

29 BNP Paribas Fortis Historical Centre, Archives Jules Dubois-Pélerin, 501, « FGTB - Holdings » (document manuscrit), 16 mai 1956.

30 BNP Paribas Fortis Historical Centre, Archives Jules Dubois-Pélerin, 501, Note confidentielle de J. Dubois-Pélerin sur l'entretien du 26 juillet 1956 avec E. de Barsy, 27 juillet 1956. 
pourrait «éviter des mesures plus graves ${ }^{131}$. Autrement dit, E. de Barsy exerce une forte pression, en décrivant sa propre solution comme le meilleur moyen d'écarter des réformes radicales (nationalisation des banques, nomination des administrateurs des banques par des instances étatiques). J. Dubois-Pélerin n'est pas encore convaincu, en août 1956, que ce geste arrêtera " les réformateurs ou démagogues de tout poil » : il estime que cela n'aurait pour effet que de "réfréner leurs appétits réformistes un instant seulement, pour repartir de plus belle ultérieurement». Dans ces négociations tendues, la formulation et le contenu du rapport annuel de la Commission bancaire deviennent une monnaie d'échange dont se sert le président E. de Barsy. Finalement, en septembre 1956, la stratégie de la Commission bancaire porte ses fruits. Impressionnée par les menaces de rendre public le non-respect du principe d'autonomie et d'apporter ainsi de l'eau au moulin des détracteurs des holdings - «d'hurler avec les loups » comme le dit le gouverneur Paul Gillet -, la Société générale parvient à persuader P. de Launoit de céder. Les deux principales sociétés de holding, la Société générale et la Brufina, s'engagent alors à céder une partie substantielle de leurs intérêts bancaires ${ }^{132}$. Pour la Société générale, le désengagement impliquerait la réduction de la participation au capital de la BSGB de 20 à $10 \%$ (vente aux actionnaires de 200000 actions sur 406 000).

Mais tout ce projet de désengagement, âprement négocié, subit un échec cuisant entre janvier et février 1957. Tant la Société générale que la Brufina ont imposé comme condition préalable à une diminution de participation que la vente d'actions prévue bénéficie d'une exemption fiscale. Durant l'été 1956, E. de Barsy s'était engagé de manière assez floue sur cette voie. Or, à l'hiver 1957, l'Administration fiscale refuse d'y consentir. Cet obstacle fiscal sonne le glas des efforts de la Commission bancaire en vue d'obtenir une plus forte indépendance des banques ${ }^{133}$.

\subsection{LE PROTOCOLE SUR L'AUTONOMIE BANCAIRE DE NOVEMBRE 1960}

C'est en 1959-1960 que le dossier de l'autonomie bancaire refait surface. Les longues négociations qui ont lieu parallèlement avec les dirigeants de la Brufina et ceux de la Société générale laissent entrevoir que les priorités de la Commission bancaire ont évolué depuis 1956-1957. Il n'est cette fois plus question de chercher à supprimer toute participation des holdings au capital de leur banque. Au contraire, E. de Barsy estime que les participations jouent un rôle en mettant en évidence " un certain degré d'intérêt public ». Il souhaiterait codifier cette participation dans un accord avec les sociétés holding: "Il s'agit de reconnaitre que deux participations bien déterminées se trouvent dans une situation particulière, ont dans l'optique du statut légal une fonction à remplir, de définir

131 BNP Paribas Fortis Historical Centre, Archives Jules Dubois-Pélerin, 501, Note confidentielle de J. Dubois-Pélerin sur l'entretien du 2 août 1956 avec E. de Barsy, s.d., p. 6.

132 R. Brion, J.-L. MOREAU, Banque nationale de Belgique, 1939-1971, op. cit., p. 500.

133 G. VAnthemsChe, "La Banque de 1934 à nos jours", op. cit., p. 316; BNP Paribas Fortis Historical Centre, Archives Jules Dubois-Pélerin, 501, Procès-verbal du conseil restreint de la Société générale de Belgique (copie), 5 février 1957. 
celle-ci autant que possible et d'en tirer une sorte de code de bon comportement ${ }^{134}$. Un peu plus tard, en novembre 1959, le président de la Commission bancaire précise les raisons qui l'ont incité à évoluer dans son analyse de la question : " Le moment est venu de changer d'optique en ce qui concerne le degré de concentration bancaire en Belgique pour examiner dorénavant celui-ci à la lumière des forces qu'il faut construire, en banque comme dans les secteurs industriels, à la dimension du Marché commun ${ }^{135}$. Pour le dire autrement, E. de Barsy préfère donner un caractère plus stable et permanent à la participation des sociétés à portefeuille dans les grandes banques de dépôt, quitte à imposer des changements de personnes dans la composition des organes dirigeants, plutôt que de favoriser le rachat par des concurrents européens des fleurons de la banque belge en imposant une réduction de la participation des holdings ${ }^{136}$.

Cette nouvelle conception de la Commission bancaire sur le statut des grandes banques de dépôt place désormais l'accent à la fois sur la stabilité et l'indépendance de celles-ci. Plus concrètement, le marché qu'E. de Barsy cherche à conclure avec les holdings leur assure une participation minimale et permanente dans le capital des banques. Corollairement, les holdings doivent accepter une subtile recomposition des conseils d'administration des banques de dépôt, qui devraient dorénavant être représentatifs de larges couches d'actionnaires et être indépendants de la haute direction de la banque ${ }^{137}$. Sur la base de ces réflexions et au terme de longues négociations, le premier " protocole relatif à l'autonomie bancaire » est signé en novembre 1960 par la Société générale et la Brufina avec la Commission bancaire. Dans son rapport annuel, cette dernière présente cet accord dans les termes suivants: "La Commission bancaire et les deux sociétés financières ont jugé opportun - sans vouloir aucunement donner à cet acte un caractère contractuel quelconque et en écartant même expressément toute idée de cet ordre - de formuler et de consigner dans un protocole l'essentiel des vues dont la communauté a été constatée et dont ces institutions se proposent de s'inspirer pour déterminer, dans l'état présent de la législation d'une part et de leurs rapports de confiance d'autre part, la ligne de conduite qu'elles ont l'intention de suivre et le cadre de leurs mutuelles consultations $»{ }^{138}$.

Cette citation insiste sur le caractère peu contraignant du protocole dont la valeur contractuelle est remise en cause d'emblée ; cet aspect répond à une ferme volonté des sociétés à portefeuille ${ }^{139}$. Il s'agit donc plutôt d'une formalisation, sous les auspices de la Commission bancaire, de quelques règles du jeu dans les rapports entre les holdings et les banques. Pratiquement, cet accord de novembre 1960 garantit la participation des holdings dans le capital des banques, en lui donnant même un caractère stabilisateur et institutionnel. Il codifie en outre des arrangements quant à la composition des organes

\footnotetext{
AGR, CBFA, 160, Procès-verbal de la Commission bancaire, 27 octobre 1959, p. 7.

AGR, CBFA, 160, Procès-verbal de la Commission bancaire, 10 novembre 1959, p. 20.

Sur ce point, cf. aussi G. VANTHEMSCHE, «La Banque de 1934 à nos jours», op. cit., p. 316 ; P. Tilly, André Oleffe, op. cit., p. 100.

137 Pour documenter ce revirement, cf. notamment BNP Paribas Fortis Historical Centre, Archives Jules Dubois-Pélerin, 501, "L'exercice autonome de la fonction bancaire. Deuxième épisode » (Note confidentielle), 10 mai 1960. Ce document interne à la BSGB résume les tractations avec la Commission bancaire entre octobre 1959 et avril 1960.

138 Commission bancaire, Rapport annuel, 1959-1960, p. 31.

139 La Société générale « insiste pour que [le protocole de novembre 1960] ne comprenne que des principes très généraux et n'ait aucun caractère contractuel » (cité dans G. VANTHEMSCHE, « La Banque de 1934 à nos jours ", op. cit., p. 318).
} 
dirigeants des banques (comité de direction et conseil d'administration) qui doivent mener à une diversification. Cette disposition trouve sa manifestation dans un renouvellement du conseil d'administration de la BSGB, qui intègre alors des personnalités du monde du commerce et de l'industrie, représentants de divers secteurs industriels et tendances politiques, assurant également un meilleur équilibre communautaire ${ }^{140}$.

Dans l'ensemble, le protocole de novembre 1960 n'apporte cependant que des modifications secondaires dans l'organisation du système bancaire belge. Il ne touche que les deux plus grandes banques, et ce de manière très souple, et ne représente pas une rupture radicale dans les relations entre banques de dépôt et sociétés financières. Au contraire, il s'inscrit dans une forte continuité et l'indépendance bancaire n'est pas entièrement garantie, à tel point que le traitement privilégié des entreprises du groupe Société générale dans l'octroi de crédits se maintient effectivement durant les années $1960{ }^{141}$. Mais, pour la Commission bancaire, le développement du Marché commun européen a changé la donne par rapport à la situation du milieu des années 1950 : conserver un ancrage belge aux principales banques du pays devient un facteur de stabilisation au moins aussi important que la mise en œuvre des principes de la scission bancaire ${ }^{142}$.

\subsection{L'AFFAIRE BONVOISIN-BROCKVILLE}

Avant de présenter les réformes apportées par le second protocole, signé en 1974, il est nécessaire de dire quelques mots d'une affaire qui affecte directement, pour la BSGB, le rapport de force avec la Commission bancaire, dans la négociation du protocole de novembre 1960. Il s'agit de l'affaire Bonvoisin-Brockville, qui se déroule essentiellement entre 1959 et 1963. Ce dossier polémique faisant déjà l'objet d'un récit relativement détaillé ailleurs, nous nous contenterons ici d'en relever les éléments pertinents pour notre analyse ${ }^{143}$. Pierre Bonvoisin, gendre de l'ancien gouverneur de la Société générale A. Galopin, devient administrateur délégué de la BSGB en 1944 ; il en exerce la présidence à partir de 1951. À l’issue des péripéties difficiles de l'année 1960, P. Bonvoisin est poussé à la démission; plus précisément, par souci de discrétion, il renonce à demander la prolongation de son mandat à la fin de 1962.

L'affaire débute par ce que les dirigeants de la BSGB appellent pudiquement l'« incident Brockville Chemicals ». En janvier 1960, la Commission bancaire a vent d'une opération d'émission publique illicite de titres de la société canadienne Brockville Chemicals Limited,

140 R. Brion, J.-L. Moreau, La Société générale de Belgique, 1822-1997, op. cit., p. 418 ; G. VANTHEMSCHE, «La Banque de 1934 à nos jours ", op. cit., p. 371.

${ }_{141}$ Ibidem, p. 319.

142 Pour la Commission bancaire, ce changement de paradigme affecte également sa politique jusqu'alors très restrictive à l'égard des fusions et des rachats effectués par les grandes banques. Cf., par exemple, AGR, CBFA, 161, Procès-verbal de la Commission bancaire, 23 août 1960, p. 16: "Aujourd'hui, compte tenu des développements économiques et politiques sur le plan européen, on peut envisager, si elles peuvent apporter une contribution réelle et vraiment constructive au fond du problème, des fusions ou associations qui auraient été accueillies de façon très réservée par la Commission jusqu'ici ».

143 P. Tilly, André Oleffe, op. cit., p. 94-107. Cf. aussi G. VANTHEMSCHE, "La Banque de 1934 à nos jours ", op. cit., p. 369-372. 
une société filiale de la Sogemines, qui elle-même fait partie du groupe de la Société générale. L'émission ne respecte pas les formalités légales du code du commerce et la Commission bancaire s'en aperçoit. Au cours de l'enquête menée ensuite par les fonctionnaires de l'autorité de surveillance, il est révélé que c'est une autre filiale du groupe de la Société générale, la Compagnie de gestion et de banque (Cogeba) - une banque fondée à Genève reprenant en partie les activités de l'ancienne filiale tangéroise de la grande banque belge ${ }^{144}$ - qui a souscrit une grande partie $(575000)$ des actions de la Brockville Chemicals. C'est la construction complexe de l'émission publique d'une société canadienne, avec une prise ferme de la part d'une autre filiale du groupe de la Société générale basée à Genève, qui constitue pour la Commission bancaire un contournement des dispositions légales belges. Plus précisément, il y a là une infraction à l'obligation de publier la notice légale d'émission publique et d'obtenir une autorisation pour le faire. Selon le président de la Commission bancaire, les soupçons se dirigent rapidement vers $\mathrm{P}$. Bonvoisin, supposé être au cœur de l'opération incriminée.

La méfiance de la Commission bancaire est de plus éveillée par la politique d'obstruction des dirigeants de la BSGB, qui se servent du secret bancaire suisse pour justifier l'impossibilité de communiquer les informations relatives à la Cogeba demandées par la Commission bancaire. Pour les superviseurs bancaires, il ne fait aucun doute que le refus de fournir les renseignements renforce " la présomption d'une fraude à la loi belge » et «d'une faute commise contre la déontologie financière " ${ }^{145}$. En plus de fortes tensions entre la Commission bancaire et les dirigeants de la BSGB et de Cogeba (P. Bonvoisin et Henri Philippe Crombé), l'incident Brockville Chemicals provoque également des frictions internes au groupe de la Société générale. Son gouverneur P. Gillet et son directeur J. Dubois-Pélerin doivent intervenir en tant qu'actionnaire principal et servir de médiateur entre P. Bonvoisin et la Commission bancaire. E. de Barsy affirme très clairement alors à $\mathrm{P}$. Gillet que l'attitude de $\mathrm{P}$. Bonvoisin à la tête de la banque pose problème : le président de la Commission bancaire fait part au gouverneur de la Société générale «de l'inquiétude croissante, extrême aujourd'hui, provoquée par les graves déviations du jugement qui se sont révélées à la présidence de la banque, déviations dont les conséquences apparaissent maintenant dans tout leur enchaînement ${ }^{146}$. L'obstacle

144 Sur l'installation en Suisse de la Cogeba, cf. ibidem, p. 365-366 et 498-499. Les documents internes conservés dans les archives de la BSGB permettent de préciser les raisons du choix de Genève. En plus des changements politiques survenus au Maroc en 1956, qui provoquent un déplacement de capitaux vers la Suisse, les dirigeants de la Société générale souhaitent concurrencer les banques suisses qui " démarchent avec succès la clientèle belge depuis 1945 ». Entre 1956 et 1962, la Cogeba connaît une forte croissance : le nombre de comptes passent de 485 à 1349, tandis que les dépôts à découvert augmentent de 124 à 472 millions de francs suisses nominaux. La Cogeba à Genève reprend une longue succession dans les filiales de la Société générale spécialisée dans la gestion de portefeuille depuis l'étranger, pour une clientèle belge (Banque belge, Londres; Banque générale du Luxembourg; Banque belge, Paris; Banque belge, New York; Compagnie belge de banque et de gestion, Tanger). La BSGB avoue également, à demi-mot, que la fraude fiscale des clients belges joue un rôle important dans les activités de la Cogeba (cf. BNP Paribas Fortis Historical Centre, BSGB, Secrétariat général, 657, Note concernant la Compagnie de gestion et de banque, Genève, 14 août 1962). Cette dimension d'évasion fiscale est confirmée dans une note interne signée par le directeur de la Société générale, J. Dubois-Pélerin : «Actuellement, Cogeba est surtout un outil - utile - de gestion de fortunes. Il s'agit de fortunes essentiellement belges et n'ayant pas la vertu de la clarté fiscale (...). Cogeba exerce un métier à la marge de ce que demande le respect de la stricte déontologie » (BNP Paribas Fortis Historical Centre, BSGB, Secrétariat général, 656, Diverses notes pour le gouverneur, 31 décembre 1962, p. 13).

145 AGR, CBFA, 161, Procès-verbal de la Commission bancaire, 9 février 1960, p. 9.

146 AGR, CBFA, 161, Procès-verbal de la Commission bancaire, 23 février 1960, p. 9. 
du secret bancaire helvétique irrite au plus haut point la Commission bancaire ; E. de Barsy estime qu'il faut «faire sauter Cogeba » ${ }^{147}$. Au cours d'un entretien avec P. Bonvoisin, le président de la Commission bancaire insiste aussi sur «l'écart considérable qu'il y avait entre le degré de considération qui pouvait, en fait, être donné ou reconnu à l'obligation de secret bancaire suisse et le respect dont il fallait témoigner pour l'institution qui, en Belgique, a le devoir de connaître la nature réelle d'actes de placement opérés dans la sphère de sa propre juridiction administrative ${ }^{148}$.

Malgré ces récriminations, l'affaire en reste là. L'émission publique délictueuse n'est pas formellement sanctionnée, mais est considérée comme le symptôme d'un dysfonctionnement dans les organes dirigeants de la banque. Il n'en reste pas moins que tout le dossier Bonvoisin-Brockville affaiblit considérablement la position de négociations des patrons de la Société générale avec la Commission bancaire autour de l'accord sur l'autonomie bancaire. E. de Barsy se sert alors du discrédit allégué de P. Bonvoisin dans l'affaire des actions Brockville Chemicals pour obtenir des concessions plus importantes dans la recomposition des organes dirigeants de la banque ${ }^{149}$.

Le dossier Bonvoisin-Brockville connaît son épilogue deux ans plus tard, en $19622^{150}$. La Commission bancaire souhaite alors régulariser la situation des titres par une cotation régulière en bourse, et soupçonne qu'une partie de la plus-value touchée par la Cogeba n'apparait pas dans les comptes. Pour tirer l'affaire au clair, un voyage secret à Genève est organisé en novembre 1962, auquel participent le président de la Cogeba, H. P. Crombé, et le directeur de la Commission bancaire, André Oleffe. Cette inspection extraordinaire est périlleuse, car interdite par la loi suisse et exceptionnelle dans les usages belges. Tout contact avec le personnel genevois de la banque est évité. Le rapport effectué

147 AGR, CBFA, 161, Procès-verbal de la Commission bancaire, 8 mars 1960, p. 7.

148 AGR, CBFA, 161, Procès-verbal de la Commission bancaire, 15 mars 1960, p. 4. Il est à noter que cette confrontation entre la Commission bancaire et une banque belge possédant une filiale en Suisse autour du secret bancaire n'est pas un cas unique. En janvier 1967, E. de Barsy cherche à nouveau à obtenir des renseignements sur les activités de la Cogeba à Genève. Il s'adresse cette fois-ci à ses homologues de la Commission fédérale des banques pour tenter de briser la résistance des banquiers belges qui se réfugient derrière le secret bancaire suisse. E. de Barsy termine son courrier par un argument relatif à la problématique croissante des filiales multinationales : "J'imagine que ce problème vous est familier et que votre institution n'accepterait pas d'ignorer, dans l'appréciation à porter sur le véritable état général des affaires, qu'une fraction importante de l'activité et des risques d'une banque suisse (et partant la mise en cause de son crédit et de sa réputation) puisse se dérouler dans le secret ou dans la pénombre d'un réseau de filiales étrangères ». Mais les superviseurs helvétiques, après une première réponse évasive, avouent leur incapacité (ou justifient-ils leur refus ?) d'aider leurs collègues belges : «Dans l'ignorance où nous sommes des raisons que peut avoir, pour agir ainsi, la filiale suisse d'une banque belge soumise à votre surveillance, nous ne pouvons, après avoir retourné ce problème de tous les côtés, que lui laisser la liberté et la responsabilité de son attitude. En aurions-nous les motifs d'ailleurs que nous ne pourrions la contraindre à fournir, à la banque de votre pays dont elle dépend, les renseignements nécessaires. Nous sommes vraiment au regret de ne pouvoir vous en dire plus " (Archives fédérales suisses [= AFS], E6520(A), 1983/50, 1, «Aufsicht der Auslandsbankbehörden über die Tochtergesellschaften und Zweigniederlassungen ausl. Banken in der Schweiz 1963-1977 », Lettre d'E. de Barsy à la Commission fédérale des banques, 26 janvier 1967, p. 7, et réponse de la CFB, 30 octobre 1967).

149 Cette hypothèse est confirmée par le bilan amer que dresse une note interne à la Société générale sur le protocole de novembre 1960 : «Compte tenu des difficultés du problème et des nombreuses pressions dont nous avons été l'objet, il eût été difficile de faire mieux » (AGR2, Fonds Société générale de Belgique, versement 4, dossier 2246, Archives Dubois-Pélerin, Procès-verbal du conseil restreint de la Société générale de Belgique, 8 novembre 1960, p. 4).

150 Toutes ces péripéties sont richement documentées dans deux dossiers conservés en BNP Paribas Fortis Historical Centre, BSGB, 656-657, « Rôle de la direction de la gestion de la filiale Cogeba », 1962-1963. 
par A. Oleffe sur ce voyage révèle la mauvaise organisation administrative de la filiale genevoise (archives disparates et non classées, conseil d'administration absent). Cette mauvaise impression est renforcée par la qualité de l'audit annuel effectué par la société de révision suisse : "Il est évident que le contrôle des réviseurs suisses (...) a été lamentablement inefficace » ${ }^{151}$, estime J. Dubois-Pélerin.

Par ailleurs, quant au fond du problème, le voyage genevois dévoile que les commissions touchées sur certaines opérations d'émission de titres, dont celles de Brockville Chemicals, ont servi à alimenter une réserve occulte. La fonction précise de celle-ci n'est pas établie avec certitude, les dirigeants de la filiale genevoise soutenant que les comptes sont prévus pour faire face à d'éventuelles difficultés (licenciements, arrestations) pour le personnel de la banque opérant dans des pays avec des risques d'instabilité politique ou économique. Dans un courrier adressé à J. Dubois-Pélerin, E. de Barsy émet une hypothèse moins optimiste quant à la nature de la réserve confidentielle, à savoir « la constitution à Genève de fonds secrets ». Il poursuit : «J'emploie ces derniers mots à dessein parce que je ne veux pas employer ceux de "caisse noire", ni surtout, en présence des explications présentées, une expression qui implique l'idée de partage. L'image la moins dure qu'on puisse évoquer est celle de la cassette aux mains d'une ou, comme en l'espèce, de plusieurs personnes, détenant par un mandat une grande autorité et qui estiment pouvoir, d'une part, user de celle-ci pour constituer des fonds par dérivation de certaines recettes - secrète pour leurs collègues ou collaborateurs, spécialement pour ceux qui ont charge des comptes - et, d'autre part, pouvoir y puiser pour accomplir des actes, de leur secteur d'autorité peut-être, mais situés en marge de son exercice ouvert et régulier ${ }^{152}$.

$\mathrm{Au}$-delà de la raison d'être exacte des fonds visés, il faut retenir au moins trois éléments. Primo, du point de vue des dirigeants et des superviseurs bancaires belges, les pratiques de surveillance bancaire suisse sont inopérantes et le secret bancaire helvétique soulève des questions de primauté des juridictions administratives difficilement solubles. Secundo, le voyage secret à Genève d'un fonctionnaire belge chargé du contrôle bancaire met en évidence l'absence de toute forme de coopération internationale sur la surveillance des entités multinationales ou extraterritoriales, alors même que ces questions deviennent pertinentes, avec l'internationalisation progressive des places financières, dès le début des années 1960. Cet épisode souligne aussi le manque de moyens - ou la mauvaise volonté ? de la Commission fédérale des banques, incapable d'obtenir des renseignements sur les opérations réalisées par la filiale genevoise d'une grande banque belge. Tertio, l'affaire Bonvoisin-Brockville permet de comprendre dans quel contexte les dirigeants des grands groupes financiers belges acceptent d'accorder à l'État, par le biais de protocoles non contraignants, une certaine influence sur la composition de leurs instances dirigeantes. In fine, P. Bonvoisin est poussé à la démission fin 1962, sur la pression du président de la Commission bancaire ${ }^{153}$.

151 BNP Paribas Fortis Historical Centre, BSGB, Secrétariat général, 656, Diverses notes pour le gouverneur, 31 décembre 1962, p. 15.

52 BNP Paribas Fortis Historical Centre, BSGB, Secrétariat général, 656, Lettre d’E. de Barsy à J. DuboisPélerin (vice-gouverneur de la SGB), 29 novembre 1962.

53 De nombreux documents d'archives internes donnent des rapports très circonstanciés sur les conditions, souvent jugées dramatiques, qui mènent à la "décapitation» de P. Bonvoisin en décembre 1962. Cf. BNP Paribas Fortis Historical Centre, BSGB, Secrétariat général, 656-657, « Rôle de la direction de la gestion de la filiale Cogeba », 1962-1963. 


\subsection{LE PROTOCOLE SUR L’AUTONOMIE BANCAIRE DE FÉVRIER 1974}

Une douzaine d'années plus tard, le $1^{\text {er }}$ février 1974, un nouveau protocole remplace l'accord conclu en $1960{ }^{154}$. Comment en arrive-t-on à ce renouvellement de la formule du gentlemen's agreement dans le domaine de l'autonomie bancaire? D'une part, la pression politique, en particulier de la part du PS, qui est en faveur d'un contrôle étatique plus étroit des holdings, se maintient et s'accentue au cours des années $1960{ }^{155}$. D'autre part, en septembre 1969, la Brufina procède à la vente de 225000 actions de la Banque de Bruxelles à l'Algemene Bank Nederland (ABN), soit la moitié de sa participation, sans en avertir la Commission bancaire ${ }^{156}$. Il s'agit là d'une violation flagrante du protocole de 1960, qui a pour effet de provoquer un nouveau débat politique, sous la forme d'une interpellation par le député socialiste Henri Simonet le 30 octobre $1969^{157}$.

Une combinaison de divers facteurs explique donc la reprise de cette thématique dans le cadre d'une troisième "commission de Voghel», en 1970. Les trois «commissions de Voghel » successives (1962, 1967 et 1970) sont des comités gouvernementaux d'études, présidés par le vice-gouverneur de la BNB et membre de la Commission bancaire F. de Voghel et mis en place pour examiner les possibilités de dynamiser l'économie belge ${ }^{158}$. Tant au niveau parlementaire que dans les débats de la commission de Voghel, c'est la forme que doit prendre l'intervention étatique qui est surtout discutée : l'autonomie bancaire est-elle finalement mieux garantie par la conclusion de gentlemen's agreement ou par l'adoption d'une législation par le Parlement? La première option, moins contraignante et préconisée par la Commission bancaire, l'emporte finalement en octobre $1972^{159}$.

Cette décision gouvernementale est saluée par les banquiers, qui attachent une grande importance à ce que le régime légal de 1935 demeure fondamentalement intact. Une note interne de la Société générale datant de septembre 1973 en témoigne : « La réalisation [du nouveau protocole] est subordonnée à une prise de position du gouvernement aux termes de laquelle ces propositions règlent correctement, sous l'angle politique des choses, le problème de l'autonomie. Elle suppose et implique que, sous réserve des adaptations prévues actuellement par le projet de loi [qui deviendra la loi du 30 juin 1975], l'économie générale de l'arrêté royal [du 9 juillet 1935] ne soit pas modifiée par le gouvernement ou

154 Sur la genèse et le contenu du protocole de février 1974, cf. Commission bancaire, Rapport annuel, 1973-1974, p. 15-38.

155 R. De PreTer, «Les socialistes et le monde bancaire», in E. Witte, R. De Preter (dir.), Histoire de l'épargne sociale: à travers l'évolution de la banque d'épargne Codep et de ses prédécesseurs, Bruxelles, Labor, 1989, p. 369-393, en particulier p. 386.

156 P.-F. SMETs, Lambert : une aventure bancaire et financière, 1831-1975, op. cit., p. 544.

157 Interpellation de H. Simonet sur «les conditions dans lesquelles le contrôle de fait d'une des plus importantes institutions bancaires belges risque d'être exercé par une institution financière étrangère et de remettre ainsi en question l'équilibre délicat de notre structure bancaire » (Chambre des représentants, Annales parlementaires, $\mathrm{n}^{\circ}$ 5, 30 octobre 1969, p. 16-21).

158 Sur les commissions de Voghel, cf. «Les travaux de la commission de Voghel », Courrier hebdomadaire, CRISP, nº 403, 1968 ; G. VANTHEMSCHE, «La Banque de 1934 à nos jours », op. cit., p. 397 et 413 ; W. PluYM, O. BoeHMe, Van de "golden sixties" tot de val van Bretton Woods, op. cit., p. 317 ; P. Tilly, André Oleffe, op. cit., p. 127-128; M. AERNOUT, De feiten achterna: de evolutie van de wetten op het financiewezen in België tussen 1969 en 1975, mémoire de maîtrise, VUB, 2016, p. 26-42.

159 G. VANTHEMSCHE, «La Banque de 1934 à nos jours », op. cit., p. 414-415. 
le Parlement ${ }^{160}$. Autrement dit, les milieux bancaires privilégient l'option d'un accord bilatéral avec la Commission bancaire, pour autant que les principes généraux du contrôle bancaire soient maintenus. On retrouve ici la préférence dominante des milieux soumis à une régulation pour la préservation du statu quo, garant d'une certaine stabilité de l'environnement institutionnel et réglementaire.

Ce choix ouvre donc la voie à la négociation du second protocole relatif à l'autonomie de la fonction bancaire, qui est signé en février 1974. Il est conclu entre la Commission bancaire, les trois plus grandes banques (Société générale de banque, Banque de Bruxelles, Kredietbank) et leurs principaux actionnaires, mais est appelé à s'étendre progressivement aux autres banques. Dans le fond, le protocole de 1974 développe et intensifie les engagements pris en $1960{ }^{161}$. Il aborde les deux volets principaux présents dès 1935 : celui de l'indépendance personnelle des dirigeants bancaires et celui de l'autonomie financière du capital social des banques. Dans le premier domaine, le protocole affirme la distinction entre le comité de direction, responsable de la gestion de la banque, et le conseil d'administration, chargé de la haute surveillance ; il définit en outre les relations entre ces deux composantes. Les nominations du président et des membres du comité de direction se font sur « avis » de la Commission bancaire, avis qui n'implique pas un véritable pouvoir d'agréation. Quant à l'autre versant, celui de l'indépendance financière, le protocole de 1974 stipule que les participations majoritaires ont un caractère presque institutionnel et contribuent à la stabilité du système bancaire. Toute modification quantitativement importante d'une participation jugée significative doit être précédée d'une consultation de la Commission bancaire, qui peut, sous certaines conditions, recommander d'en suspendre la réalisation.

Comme en 1960, les dispositions disciplinaires du protocole sont faibles : aucune sanction formelle n'est prévue en cas de transgression. "Une concertation s'établira au niveau le plus adéquat », mentionne simplement le texte. Une communication publique de nonrespect semble être la menace la plus lourde envisagée. L'entérinement du protocole donne lieu à une certaine agitation politique. Négocié essentiellement par le président démissionnaire de la Commission bancaire, le social-chrétien A. Oleffe, qui est nommé ministre des Affaires économiques en avril 1974, et par le ministre des Finances, le libéral Willy de Clercq, le protocole est remis en question par le ministre socialiste Willy Claes, qui accuse A. Oleffe d'avoir agi sans l'accord de la majorité gouvernementale ${ }^{162}$. Malgré ces protestations, le protocole est maintenu ; jusque dans les années 1990, il définira le fonctionnement du système bancaire belge.

Il ressort clairement des éléments développés ci-dessus que la garantie de l'indépendance des banques à l'égard des sociétés de holding dont elles sont issues est une notion dont la définition évolue au cours des quarante premières années d'existence de la Commission bancaire. Dans un premier temps, entre 1935 et 1954, ce dossier ne constitue pas une priorité absolue pour les superviseurs. Ceux-ci, bien conscients du caractère purement

160 Note «Autonomie - Structure d'administration des banques », annexée au procès-verbal du comité directeur de la Société générale, 7-10 septembre 1973 (citée dans ibidem, p. 400).

${ }^{161}$ Une copie du protocole signé par la Société générale est conservée dans AGR2, Fonds Société générale de Belgique, versement 4, dossier 698, Secrétariat général.

162 G. VANTHEMSCHE, «La Banque de 1934 à nos jours », op. cit., p. 418 ; P. Tilly, André Oleffe, op. cit., p. 141. Sur le parcours d'André Oleffe, cf. aussi P. WYNANTS, «André Oleffe et le fédéralisme : du rejet à l'acceptation résignée (1961-1972) », Courrier hebdomadaire, CRISP, n 1954, 2007. 
formel de la scission opérée en 1934, se contentent d'accorder des dérogations aux dirigeants bancaires pour leur permettre de maintenir certains mandats d'administrateur dans des sociétés commerciales. Entre 1954 et 1957, au cours d'échanges souvent conflictuels avec les milieux bancaires, la Commission bancaire cherche à imposer une réduction massive, voire une suppression, de la participation des sociétés à portefeuille dans le capital de leurs filiales bancaires. Puis, au cours d'une troisième phase, entre 1960 et 1975, la politique de la Commission bancaire se caractérise par une approche de concertation avec les dirigeants bancaires, qui se concrétise par la ratification de deux protocoles. Ces accords ont pour effet non pas de réduire, mais de stabiliser l'actionnariat principal des grandes banques.

Cette évolution s'effectue dans le contexte de la construction du Marché commun européen et de l'affirmation de grands groupes européens. Garantir un ancrage belge semble alors devenir un objectif prioritaire, au détriment des principes généraux de scission hérités des années 1930. Pour le dire autrement, un glissement de priorités s'opère chez la Commission bancaire entre les années 1950 et les années 1960 : les risques de voir des fleurons de la finance belge tomber sous l'influence de groupes étrangers, à l'heure de la construction européenne, sont considérés comme une plus grande menace que le manque d'indépendance des banques de dépôt à l'égard des sociétés holdings auxquelles elles sont étroitement liées. 


\section{L'EXTENSION DES DOMAINES DE COMPÉTENCES DE LA COMMISSION BANCAIRE (1957-1975)}

La Commission bancaire est initialement conçue comme un organisme chargé de chapeauter la mise en application d'une réglementation bien précise, l'arrêté royal du 9 juillet 1935, texte qui l'institue. À cet égard, elle est, selon le régime prévu en 1935, exclusivement chargée du contrôle de deux types d'activité et d'entités : les banques de dépôt et les émissions de titres. À cette double mission correspond l'organisation interne de la Commission bancaire, dont les services administratifs se composent essentiellement, jusqu'en 1965, de deux départements distincts, mais complémentaires : celui du contrôle des banques et celui du contrôle des émissions ${ }^{163}$. Alors que la première compétence, celle du contrôle bancaire, a été considérée comme l'essentielle pendant la première décennie d'activité de la Commission - en raison notamment du faible volume des émissions pendant les années de guerre -, la dynamique se renverse au cours de l'aprèsguerre : le contrôle des émissions prend une importance croissante ${ }^{164}$.

Dans ce régime, toute une série d'acteurs importants de la vie financière belge échappe intégralement au contrôle de la Commission bancaire ${ }^{165}$. D'une part, les nombreuses institutions parastatales de crédit ne sont pas visées : la $\mathrm{BNB}$, l'Institut de réescompte et de garantie (IRG), la Caisse générale d'épargne et de retraite (CGER), la Société nationale de crédit à l'industrie (SNCI), le Crédit communal de Belgique, la Caisse nationale de crédit professionnel, l'Office central de crédit hypothécaire (OCCH) et l'Institut national de crédit agricole (INCA). D'autre part, jusqu'en 1975, les caisses d'épargne privées, réglementées par un arrêté royal de décembre 1934 et supervisées dès lors par une autre agence de régulation, l'Office central de la petite épargne, ne sont pas soumises à la surveillance de la Commission bancaire. Enfin, bien évidemment, les sociétés à portefeuille, ou sociétés financières, ne sont pas non plus assujetties.

En une vingtaine d'années, entre 1957 et 1975, la Commission bancaire connaît un élargissement significatif de ses compétences de contrôle. Cette extension progressive des administrés est liée à l'évolution des techniques innovantes des appels publics à l'épargne. Chaque nouvelle technique d'investissement ouvre une brèche dans le système

163 Dans l'organigramme du secrétariat, un troisième service existe, intitulé «Études et documentation », qui collabore dans les deux domaines principaux.

64 A. BRUYNEEL, «De quelques observations relatives aux compétences et aux pouvoirs de la Commission

bancaire ", Revue de la banque, volume 36, n 3, 1972, p. 210.

65 Arrêté royal du 9 juillet 1935 sur le contrôle des banques et le régime des émissions de titres et valeurs, Moniteur belge, 10 juillet 1935, titre I, article 1. 
de contrôle, qu'il s'agit de colmater en confiant une nouvelle mission de surveillance à la Commission bancaire. Cet élargissement, du point de vue juridique, est balisé par quatre étapes. Primo, en 1957, les fonds communs de placement sont placés sous la surveillance de la Commission bancaire. Secundo, en 1964, celle-ci doit également contrôler toutes les entreprises qui, en dehors des banques et des caisses d'épargne privées, reçoivent des fonds en faisant appel au public : il s'agit essentiellement de sociétés spécialisées dans le crédit à la consommation ou le crédit hypothécaire ${ }^{166}$. Tertio, en 1967, les sociétés à portefeuille ou holdings sont soumises à une réglementation très timide et lacunaire ; la Commission bancaire n'obtient un pouvoir d'intervention que dans le domaine de l'information au public et aux actionnaires, si bien qu'il est difficile de parler de contrôle. Quarto et enfin, en 1975, la Commission bancaire reçoit la surveillance des caisses d'épargne privées, dans le cadre du mouvement de déspécialisation des entreprises financières. En raison du peu d'informations qualitatives dont nous disposons sur l'application par la Commission bancaire de ces quatre nouvelles compétences de surveillance, nous ne ferons que survoler brièvement ces évolutions ${ }^{167}$.

\section{1. LES FONDS COMMUNS DE PLACEMENT}

En mars 1957, le Parlement belge adopte une loi relative aux fonds communs de placement ${ }^{168}$. L'impulsion initiale de cet acte législatif remonte à 1954-1955, lorsque le ministre des Finances, le libéral H. Liebaert, met sur pied une commission en vue de préparer un projet de contrôle de cette forme d'appel à l'épargne. Pour rappel, les fonds communs de placement, aussi connus ailleurs sous l'appellation investment trust, sont des placements collectifs de valeurs mobilières qui, ensemble, forment une masse indivise. Comme ailleurs, leur succès repose, pour le dire rapidement, sur la simplicité d'acquisition, la discrétion, les avantages fiscaux et la répartition des risques inhérents à cette forme d'investissement. En Belgique, ils font leur apparition, sans doute sur le modèle néerlandais - précurseur dans ce domaine en Europe continentale -, dès les premières années d'aprèsguerre. Dès mai 1946, la Commission bancaire discute d'une émission réalisée par une société de gestion de fonds communs de placement ${ }^{169}$. Il s'agit de la Belgische Maatschappij voor Beleggingsbeheer (BEMAB), une société créée par le holding Algemeene Maatschappij voor Nijverheidskrediet, proche de la Kredietbank. Les fonds communs de valeurs mobilières s'apparentent essentiellement aux investment trusts anglo-saxons. Entre 1947 et 1949 , la BEMAB fonde au moins trois fonds spécialisés dans les valeurs respectivement britanniques, états-uniennes et belges (Engels Depot, Dollar Depot, Belgisch Depot) ${ }^{170}$. Un peu plus tard, la Banque Lambert lance son propre outil d'investissement, en constituant en août 1955, par l'intermédiaire de la Société de gestion des fonds de placement (Soges) - filiale créée pour l'occasion -, le Fonds international de placement. En septembre 1956,

166 A. BRUYNEEL, « La Commission bancaire belge », op. cit., p. 249.

67 Il est à cet égard regrettable que les archives de la Commission bancaire ou de la BNB ne contiennent pas, à notre connaissance, de dossiers thématiques sur ces questions-là.

168 Loi du 27 mars 1957 relative aux fonds communs de placement et modifiant le Code des droits de timbre et le Code des taxes assimilées au timbre, Moniteur belge, 13 avril 1957.

169 AGR, CBFA, 147, Procès-verbal de la Commission bancaire, 21 mai 1946.

170 P.-F. SMETS, Lambert : une aventure bancaire et financière, 1831-1975, op. cit., p. 256. 
c'est la Société belge de banque qui franchit le pas avec la SA Geva. Avant l'adoption de la loi du 27 mars 1957, six sociétés de fonds communs de placement sont déjà actives en Belgique ${ }^{171}$.

En 1954-1955, un projet de légiférer sur cet objet est envisagé. Le Comité national pour le développement de l'épargne mobilière, présidé par le président de la Banque de Bruxelles, M.-L. Gérard, fournit alors un premier avant-projet à la commission ad hoc créée par le ministre des Finances, H. Liebaert ${ }^{172}$. La Commission bancaire s'empare du dossier dès janvier 1955. Ses membres sont unanimement favorables à une législation, notamment pour contrer « les déviations qui pourraient s'installer si des dispositions efficaces n'étaient pas prises $"{ }^{173}$. Le débat s'achève sur une prise de position claire : «Il faut répondre affirmativement à la question de savoir s'il y a lieu ou non de légiférer dans ce domaine. [Les membres de la Commission bancaire] inclinent à penser que la législation devrait être très complète ; elle devrait toucher à la fois au statut civil de ces fonds communs, c'est-à-dire donner forme à cette institution juridique nouvelle et, d'autre part, étudier le contrôle de la création et du fonctionnement des fonds communs. (...) L'institution de contrôle paraît devoir être la Commission bancaire $"{ }^{174}$. Les superviseurs adhèrent à une réglementation de cette nouvelle technique d'investissement. En raison de la complexité du dossier, ils recommandent en outre l'adoption d'une loi brève qui délègue à la Commission bancaire une grande marge de manœuvre pour la mise en exécution du statut légal.

La Commission bancaire obtient raison, puisque c'est en effet une loi-cadre qui est votée en mars 1957, c'est-à-dire que le texte promulgué ne fixe que des principes très généraux et délègue à un établissement, ici la Commission bancaire, la puissance exécutive à proprement parler ${ }^{175}$. En vertu de ce pouvoir discrétionnaire, la Commission bancaire promulgue, en avril 1958, un règlement qui fixe les droits et obligations des sociétés de gestion de fonds communs de placement. Dans le cadre de cet ensemble de réglementations, la Commission bancaire s'octroie des attributions précises dans le domaine des fonds communs de placement ${ }^{176}$. Elle obtient un pouvoir d'agréation des sociétés de gestion des fonds; sans cette autorisation, une entreprise ne peut pas s'établir. En cas de non-respect de la réglementation, cette agréation peut être retirée par la Commission bancaire, ce qui provoque la mise en liquidation de la société de gestion. En outre, l'autorité de surveillance dispose d'un pouvoir d'investigation dans les documents et écritures des sociétés de gestion, elle peut exiger la communication de toute information relative à leur activité. Enfin, la prise en charge de cette nouvelle mission implique une nouvelle source de financement pour la Commission bancaire. La

171 Ibidem, p. 265.

P. Tilly, André Oleffe, op. cit., p. 80-81. Le groupe de travail chargé de préparer l'avant-projet comprend des représentants de l'Administration des Finances, de la BNB, de l'ABB, de la Commission de la Bourse de Bruxelles, du Comité national pour le développement de l'épargne mobilière et de la Commission bancaire. Cf. AGR, CBFA, 156, Procès-verbal de la Commission bancaire, 26 avril 1955, p. 9.

173 AGR, CBFA, 156, Procès-verbal de la Commission bancaire, 11 janvier 1955, p. 11.

174 AGR, CBFA, 156, Procès-verbal de la Commission bancaire, 11 janvier 1955, p. 12.

175 W. DECAMP, J. VERTENEUIL, «Quelques réflexions sur le statut légal des fonds communs de placement en Belgique ", Revue de la banque, volume 31, n 8, 1967, p. 725.

176 F. REQUETTE, Les fonds communs de placement en Belgique, Bruxelles, Bruylant, 1968, p. 165-184. 
rémunération annuelle touchée auprès des sociétés de gestion dépend de la valeur globale des fonds communs gérés $\left(0,1 \%\right.$ en avril 1958) ${ }^{177}$.

Il semble que, globalement, l'application de la loi sur les fonds communs de placement ne pose pas de grandes difficultés à la Commission bancaire ${ }^{178}$. Selon le spécialiste en droit financier André Bruyneel, qui s'exprime en 1972, le contrôle des fonds de placement n'a pas engendré de conséquences particulières pour la Commission bancaire «à cause de l'insuccès relatif qu'a connu en Belgique l'épargne sous forme de parts de fonds communs de placement $»{ }^{179}$. Il est vrai que le nombre de sociétés de gestion et de fonds administrés est relativement stable : entre 1958 et 1972, le nombre de sociétés de gestion agréées par la Commission bancaire fluctue entre 4 et 6 , tandis que le nombre de fonds communs de placement belges administrés par cette poignée de sociétés passe de 8 à $10^{180}$. En se basant sur les chiffres de 1969, A. Bruyneel estime que la part de l'épargne investie dans les fonds communs de placement est relativement modeste : elle s'élève au total à 12,4 milliards de francs belges, contre 32,8 milliards d'accroissement pour les dépôts bancaires, 27 milliards pour l'épargne hypothécaire et immobilière, et 21,2 milliards pour les placements en actions et obligations ${ }^{181}$.

\subsection{LE CONTRÔLE DES ENTREPRISES QUI COLLECTENT DES FONDS EN FAISANT APPEL AU PUBLIC (1964)}

Le deuxième élargissement significatif des compétences de la Commission bancaire se produit en 1964, année durant laquelle une loi est adoptée par le Parlement pour combler une lacune de la réglementation existante ${ }^{182}$. Il s'avère en effet qu'un secteur de collecte de fonds complètement dérégulé s'est développé, en dehors du système bancaire conventionnel et de tout contrôle légal : jusqu'alors, rien n'empêche une entreprise, aussi longtemps qu'elle n'est pas considérée comme une banque, de solliciter l'épargne publique selon des formules parfois douteuses ${ }^{183}$.

La loi du 10 juin 1964 vient sanctionner une situation problématique que la Commission bancaire stigmatise régulièrement depuis le début des années 1950, à savoir l'existence de certains modes d'appel public au marché effectué en marge des dispositions et des contrôles légaux ${ }^{184}$. Elle estime par exemple en 1955 que, «dans un système où toutes les formes usuelles d'appel public à l'épargne sont surveillées, l'existence de secteurs non contrôlés est susceptible de susciter des initiatives douteuses et de nuire au climat général du marché ${ }^{185}$. Un exemple typique de ce type d'appel à l'épargne est celui des sociétés

${ }_{177}$ Cf. T. GIDDEY, « Formation et spécificités historiques de la Commission bancaire (1935-1975) », op. cit.

178 P. Tilly, André Oleffe, op. cit., p. 81.

179 A. BRUYNEEL, « La Commission bancaire belge », op. cit., p. 248.

Rapports annuels de la Commission bancaire pour les années correspondantes.

181 A. BRUYNEEL, «La Commission bancaire belge », op. cit., note 317, p. 248.

182 Loi du 10 juin 1964 sur les appels publics à l'épargne, Moniteur belge, 20 juin 1964.

183 G. GELDERS, "La Commission bancaire : 45 ans d'histoire de la législation financière ", Revue de la banque, $n^{\circ} 8 / 9,1980$, p. 59 : «Des escroqueries conduisirent le législateur à intervenir », ajoute celui qui était alors conseiller au service d'études et documentation de la Commission bancaire.

184 Cf., par exemple, Commission bancaire, Rapport annuel, 1951-1952, p. 68-70.

185 Commission bancaire, Rapport annuel, 1954-1955, p. 10. 
spécialisées dans le financement à tempérament, autrement dit le crédit à la consommation, qui réalisent souvent des profits très élevés.

Pour mettre fin aux différents abus et opérations proches de l'escroquerie, la législation de 1964 affirme le principe selon lequel la collecte de dépôts d'argent du public est réservée à des entreprises soumises à des contrôles protecteurs de l'épargne. Toute réception de fonds du public réalisée en dehors des organismes financiers soumis à un contrôle devient un délit ${ }^{186}$. Par cette législation, un nouveau secteur - par ailleurs très hétérogène - est donc soumis au contrôle de la Commission bancaire. En effet, les sociétés, désignées par la formule d'« entreprises régies par le chapitre $1^{\text {er }}$ de la loi du 10 juin 1964 », sont désormais administrées par un statut légal très proche de celui des banques : elles doivent être inscrites officiellement, respecter des règles d'organisation formelle, se soumettre à un contrôle révisoral, et communiquer des informations à la Commission bancaire.

Selon A. Bruyneel, cette nouvelle compétence n'entraîne pas de conséquences importantes pour la Commission bancaire. Celle-ci doit toutefois adapter ses moyens d'intervention à des entreprises de taille modeste. Le service administratif que la Commission bancaire dévoue au contrôle de ce domaine reste le moins bien doté en personnel : en 1976, lorsqu'un organigramme plus précis du secrétariat sera publié, la section sur le contrôle des entreprises régies par le chapitre $1^{\text {er }}$ de la loi du 10 juin 1964 ne comptera qu'une employée, contre 9 pour le contrôle des banques, 5 pour le contrôle des émissions de titres et des fonds de placement, 2 pour le contrôle de caisses d'épargne privées, et 2 pour le contrôle des sociétés à portefeuille ${ }^{187}$. En 1975, le statut légal des entreprises qui font appel à l'épargne est modifié par la loi dite Mammouth (cf. infra). Dans l'esprit de déspécialisation qui caractérise cette législation, le régime de contrôle, dans certaines de ses exigences, se rapproche de celui d'autres intermédiaires financiers ${ }^{188}$.

\subsection{LA RÉGLEMENTATION SUR LES SOCIÉTÉS À PORTEFEUILLE OU HOLDINGS (1967)}

Troisièmement, par un arrêté royal du 10 novembre $1967^{189}$, la Commission bancaire reçoit un nouvel élargissement de compétences. Cette intervention trouve son origine dans les recommandations émises par la commission gouvernementale pour l'étude des problèmes de financement de l'expansion, dite deuxième commission de Voghel. Il s'agit d'une législation très timide, qui n'entraîne pas l'assujettissement intégral des sociétés à portefeuille (à savoir les fameux holdings issus de la scission bancaire de 1934, comme la Société générale ou la Brufina). Ces dernières ne sont pas soumises à une surveillance similaire à celle des banques, qui impliquerait le respect de certains ratios prudentiels ou un contrôle externe permanent et obligatoire. L'arrêté royal du 10 novembre 1967 cherche essentiellement à atteindre deux objectifs : associer les sociétés

186 A. BRUYNEEL, « La Commission bancaire belge », op. cit., p. 248.

187 Commission bancaire, Rapport annuel, 1975-1976, p. 11-12. Dix autres salariés seront alors employés dans des services à portée générale (études, documentation, secrétariat, inspection, informatique, etc.).

188 J. Le Brun, C. Lempereur, La protection de l'épargne publique et la Commission bancaire, op. cit., p. 240.

189 Arrêté royal du 10 novembre 1967 organisant le statut des sociétés à portefeuille et leur association à la programmation économique, Moniteur belge, 14 novembre 1967. 
à portefeuille à la programmation économique et améliorer la qualité de l'information donnée à leurs actionnaires et au public ${ }^{190}$. Même le juriste A. Bruyneel, pourtant détracteur convaincu des solutions interventionnistes, estime en 1972 que "l'arrêté constitue une première tentative de réglementation des holdings; son origine, ses lacunes et ses timidités manifestes expliquent, entre autres facteurs, l'application très réservée qui en a été faite jusqu'ici » ${ }^{191}$.

Le premier objectif - l'association à la programmation économique - consiste foncièrement en une communication facultative des projets d'investissement du holding à un organisme d'intérêt public, le Bureau du plan ${ }^{192}$. Il ne concerne donc pas la Commission bancaire. Quant au second objectif - l'information correcte des actionnaires et du public, il vise à être atteint par des dispositions qui donnent à la Commission bancaire le pouvoir d'adresser des observations à une société concernant la qualité des renseignements publiés de son bilan, ses comptes et son rapport aux actionnaires. En ce sens, l'action de la Commission bancaire se rapproche ici de son intervention dans le domaine des émissions de titres et valeurs : il s'agit là simplement de vérifier la pertinence des informations contenues dans le prospectus d'émission.

La mise à exécution de l'arrêté royal du 10 novembre 1967 par la Commission bancaire s'effectue lentement. En janvier 1971, les procès-verbaux du conseil restreint du principal holding, la Société générale, relatent que la Commission bancaire se contente d'une application minimale : " [La Commission bancaire] estime, après examen des sociétés soumises à l'arrêté, qu'il n'est pas possible d'établir des normes générales et que son action doit se limiter à veiller à ce que chaque société donne au public, en particulier dans son rapport annuel, une image exacte d'elle-même $"{ }^{193}$. Il n'est donc pas étonnant que, en mars 1971, le député socialiste H. Simonet dépose une proposition de loi visant à augmenter les pouvoirs de la Commission bancaire à l'égard des holdings ${ }^{194}$. Ce dernier avance que, depuis l'entrée en vigueur de l'arrêté royal du 10 novembre 1967, aucune amélioration n'est perceptible dans le domaine: "Il était permis d'espérer que les recommandations ou interventions pragmatiques et concrètes de la Commission bancaire auraient pu aboutir dans ce domaine comme dans celui des émissions publiques de titres à un assainissement des structures de groupes de sociétés et à l'élimination des pratiques inspirées par des convenances de groupes plutôt que par l'intérêt général, régional ou sectoriel. Malheureusement, il n'en fut rien ${ }^{195}$. Ce projet n'aboutit pas.

Au cours des années 1970, le contrôle exercé par la Commission bancaire sur les holdings se cantonne à une action de recommandation sur l'exactitude et la complétude des informations aux actionnaires. En 1979, le directeur de la Commission bancaire, Herman

190 G. GELDERS, « La Commission bancaire », op. cit., p. 61.

191 A. BRUYNEEL, « La Commission bancaire belge », op. cit., p. 250.

192 Près de cinq ans après l'adoption de l'arrêté royal du 10 novembre 1967, les procès-verbaux du conseil restreint de la Société générale précisent que «l'association des sociétés à portefeuille à la programmation économique générale est restée, jusqu'ici, lettre morte»(AGR2, Fonds Société générale de Belgique, versement 4, dossier 699, Secrétariat général, Procès-verbal du conseil restreint (extraits), 6 avril 1971). Les interactions avec le Bureau du plan ne semblent débuter qu'en 1973.

193 AGR2, Fonds Société générale de Belgique, versement 4, dossier 699, Secrétariat général, Procèsverbal du conseil restreint (extraits), 12 janvier 1971.

194 Chambre des représentants, Proposition de loi modifiant et complétant l'arrêté royal du 10 novembre 1967 organisant le statut des sociétés à portefeuille et leur association à la programmation économique, $\mathrm{n}^{\circ}$ 922/1, 9 mars 1971.

Ibidem, p. 1. 
Biron, porte encore un regard critique sur la portée de la surveillance : « Le contrôle des sociétés à portefeuille a hérité de la plupart des ambiguités de l'objet sur lequel il porte. En pratique, ce contrôle est devenu celui de l'information publiée par ces sociétés » ${ }^{196}$.

\subsection{LE CONTRÔLE DES CAISSES D’ÉPARGNE PRIVÉES ET LA LOI MAMMOUTH (1975)}

Quatrièmement et enfin, la Commission bancaire reçoit en 1975 la mission de contrôler les caisses d'épargne privées. Cet élargissement s'intègre plus largement dans le paquet de mesures ficelées dans la loi du 30 juin 1975 relative au statut des banques, des caisses d'épargne privées et de certaines autres intermédiaires financières ${ }^{197}$, aussi surnommée loi Mammouth. Celle-ci trouve son origine dans les conclusions de la troisième commission de Voghel, remises au gouvernement en novembre $1970{ }^{198}$. L'un des objectifs principaux du projet de loi négocié entre 1974 et 1975 est de favoriser la tendance à la déspécialisation, et, partant, l'adaptation du cadre réglementaire belge aux pratiques en vigueur dans la Communauté économique européenne (CEE) ${ }^{199}$. Par déspécialisation des institutions de crédit, il faut entendre l'évolution qui tend à uniformiser les opérations financières effectuées par les différents intermédiaires financiers (banques de dépôt, caisses d'épargne privées, institutions publiques de crédit, etc.).

Brossé à grands traits, le compromis fondamental qui sous-tend la réforme de juin 1975 consiste à renforcer les pouvoirs de la Commission bancaire, notamment dans ses capacités d'intervention et de sanction auprès des réviseurs et de ses administrés, ainsi que dans la définition des mesures prudentielles et des obligations de publicité comptable. Ce renforcement des prérogatives de la Commission bancaire est toutefois compensé par une remise en question progressive de la stricte scission des activités imposée en 1934, dans le sens d'une déspécialisation ${ }^{200}$. Le « verrou fondamental » de l'interdiction pour les banques de dépôt de détenir des participations permanentes dans des sociétés commerciales saute alors. Si le principe de la proscription de la banque mixte est

196 H. BIRON, «Le contrôle de l'information publiée par les sociétés à portefeuille », Revue de la banque, $\mathrm{n}^{\circ} 1,1979$, p. $59-78$.

197 Moniteur belge, 2 août 1975.

198 La troisième commission de Voghel a été mise sur pied à la suite des remous politiques suscités par l'incident de la vente par la Brufina d'un paquet d'actions de la Banque de Bruxelles à la banque néerlandaise $\mathrm{ABN}$ (cf. supra). Chapeautée par la BNB, elle est composée de plusieurs personnalités importantes du monde financier belge : F. De Voghel, R. Beauvois, H. Vloeberghs (tous trois BNB), L. Aerts, P. Frantzen (tous deux CGER), W. Fraeys (SNCI), M. Van Audenhove (Crédit communal), Henri Neuman (SNI), E. de Brabandère (ABB), J. Godeaux (Banque Lambert), A. Lamfalussy (Banque de Bruxelles), R. Lamy (Société générale), L. Wauters, E. Thielemans (tous deux Kredietbank), H. Detremmerie (Caisse centrale de dépôts $\mathrm{COB}$ ), M. Leclercq (Coop-Dépôts), R. Ramaekers (FEBECOOP), L. Lindemans (CSC), A. Oleffe, J. Verteneuil, H. Baeyens (tous trois Commission bancaire), Christian d'Hoogh (ULB), L. Levy (Universiteit van Antwerpen), P. Callebaut (Office central de la petite épargne), M. D'Haeze, M. Esselens, E. Kestens (tous trois Administration de la Trésorerie et de la Dette publique). Cf. M. Aernout, De feiten achterna, op. cit., p. 31-33.

199 Pour une étude historique sur la loi du 30 juin 1975, cf. M. AERNOUT, De feiten achterna, op. cit., p. 43-66.

D. YeRnAULT, L'État et la propriété. Le droit public économique par son histoire (1830-2012), Bruxelles, Bruylant, 2013, p. 698-702. 
formellement maintenu en 1975, les assouplissements et aménagements prévus ouvrent la voie à un décloisonnement ultérieur.

Le déroulement chronologique de l'élaboration de la loi du 30 juin 1975 est jalonné de plusieurs événements qui l'influencent : la nomination de Jean Godeaux, ancien directeur de la Banque Lambert, à la tête de la Commission bancaire en juin 1974, l'annonce en octobre 1974 d'un accident de change subi par la Banque de Bruxelles (quelques mois après la faillite de la banque allemande Herstatt, qui déclenche une crise internationale sur le marché des changes), puis l'ouverture d'instructions judiciaires en mars 1975 au sujet de transferts de capitaux illicites (fraude fiscale) opérés par la Banque de Bruxelles vers ses filiales luxembourgeoise et genevoise ${ }^{201}$. Ces trois événements et les discussions politiques qu'ils provoquent contribuent à modifier le projet de loi en cours d'examen. Les amendements gouvernementaux concernent essentiellement le renforcement des prérogatives de la Commission bancaire (droit de contrôle direct sur les banques, au caractère cependant discontinu), ainsi que l'intégration d'une clause qui autorise la Commission bancaire à intervenir si elle détecte un "mécanisme particulier ayant pour but ou pour effet de favoriser la fraude fiscale ».

Pour en revenir à la question de l'élargissement des entreprises soumises au contrôle de la Commission bancaire, la loi du 30 juin 1975 produit à ce titre une réorganisation de l'architecture de la régulation financière. Au nom de la déspécialisation, l'Office central de la petite épargne, un organisme créé en décembre 1934 et de fait placé sous la dépendance de la BNB, est phagocyté par la Commission bancaire, qui hérite de ses compétences dans le contrôle des caisses d'épargne privées. En plus du changement de superviseur, les caisses d'épargne doivent s'adapter à un régime plus proche de celui des banques, ce qui implique notamment le respect de plusieurs prescriptions (capital minimal, fonds propres, contrôle révisoral, etc.) ${ }^{202}$.

L'attribution à la Commission bancaire de ce nouveau statut légal achève le mouvement de centralisation des tâches de contrôle initiée en 1957 avec la prise en charge des fonds communs de placement. Dès 1972, le spécialiste de droit bancaire A. Bruyneel anticipe cette évolution: "Les quinze dernières années montrent une tendance très marquée à la multiplication des compétences de la Commission bancaire. (...) Cette marche accélérée à l'élargissement témoigne de deux tendances, salutaires dans leur principe, mais parfois délicates dans leurs conséquences : d'une part, l'amélioration de la protection de l'épargne en matière de valeurs mobilières et autres titres de participation ou d'emprunt, d'autre part, la centralisation progressive des organismes financiers ${ }^{203}$.

En 1975, la Commission bancaire concentre désormais auprès d'elle l'intégralité des contrôles des intermédiaires financiers du secteur privé. Ce réagencement des responsabilités entre acteurs de la régulation financière implique également un nouvel équilibre entre la BNB et la Commission bancaire. Cette évolution s'inscrit, là aussi, dans la continuité de mesures prises dès 1973. Avec la suppression de l'Office central de la petite épargne, la BNB perd de fait une compétence de contrôle, mais, en revanche, elle obtient un accroissement de ses pouvoirs dans la définition des coefficients qui ont

201 A. BRUYNEEL, « La loi du 30 juin 1975 », op. cit., p. 650. Sur les transferts illégaux de capitaux, cf. P.-F. SMETS, Lambert : une aventure bancaire et financière, 1831-1975, op. cit., p. 591-592.

202 A. BRUYNEEL, « La loi du 30 juin $1975 »$, op. cit., p. 651-652.

203 A. BRUYNEEL, « La Commission bancaire belge », op. cit., p. 252. 
un impact sur la politique monétaire. Pour le dire autrement, la réforme de 1975 confirme la tendance selon laquelle la régulation financière macro-prudentielle (détermination des réserves monétaires, stabilité systémique) revient à la $\mathrm{BNB}$, tandis que la surveillance micro-prudentielle (contrôle révisoral, respect du coefficient de fonds propres) - dorénavant appliquée à tous types d'établissements financiers privés - reste l'apanage de la Commission bancaire.

La loi du 30 juin 1975, avec l'élargissement et le renforcement des pouvoirs de la Commission bancaire qu'elle provoque, constitue sans aucun doute un tournant dans l'histoire de l'autorité de surveillance. Elle justifie largement que nous interrompions là notre analyse des premières années d'existence de l'institution. Il faudra en effet attendre la loi du 22 mars 1993 relative au statut légal et au contrôle des établissements de crédit ${ }^{204}$ pour voir la prochaine réforme d'importance s'engager ; la tendance à la déspécialisation y sera alors accentuée. Plus tard encore, en 2008-2009, le gouvernement belge, dans le contexte de la crise des subprimes, prendra d'urgence des mesures relatives à la stabilité financière ${ }^{205}$. Plus largement encore, la loi du 30 juin 1975 marque également une étape vers la dérégulation du secteur bancaire ${ }^{206}$. La déspécialisation implique certes un renforcement quantitatif des compétences de la Commission bancaire, mais il signifie également un rapprochement entre les différentes catégories d'institutions financières et la suppression progressive des barrières qui confinent les établissements dans certaines gammes d'opérations.

204 Moniteur belge, 19 avril 1993.

205 Sur les évolutions récentes de la régulation financière belge, cf. D. YeRnAULT, L'État et la propriété, op. cit., p. 1025-1087 ; X. DieuX, Droit, morale et marché, Bruxelles, Bruylant, 2013, p. 509-546 ; J. MiTCHELL, P. VAn Roy, C. VesPro, «Ten Years after the Financial Crisis: Regulatory Reforms and the Belgian Banking Sector ", Reflets et perspectives de la vie économique, volume 61, $\mathrm{n}^{\circ} 1,2017$, p. 9-28.

206 J.-L. MOREAU, "Contrôler sans nationaliser. Le contrôle bancaire en Belgique de 1935 à 1974 ", in V. DUjARDin et al. (dir.), La crise économique et financière de 2008-2009. L'entrée dans le $21^{e}$ siècle?, Bruxelles, Peter Lang, 2010, p. 119. 


\section{CONCLUSION GÉNÉRALE}

Quel bilan général tirer des spécificités de la régulation bancaire, tel qu'elle se manifeste en Belgique entre 1935 et 1975 ?

Les origines du régime de contrôle des banques remontent aux années 1930. Malgré une grave crise financière, les autorités belges mettent en place un système de contrôle fort peu contraignant pour les agents bancaires. Ce système est inspiré de la très libérale loi fédérale suisse sur les banques (1934), alors que d'autres modèles (États-Unis, Scandinavie) auraient été envisageables. Il existe cependant une particularité spécifique aux réformes opérées en Belgique en 1934-1935 : elles combinent des réformes structurelles profondes, sous la forme de la scission des banques mixtes, avec un régime de surveillance étatique minimaliste.

La Commission bancaire qui est alors mise en place demeure très longtemps un organisme très léger en ce qui concerne les moyens disponibles, à la fois dans son budget et dans le nombre de ses collaborateurs. Cette faiblesse bureaucratique s'explique notamment par le système de contrôle indirect, qui confie en premier lieu la vérification de la conformité des banques avec la loi à un corps de réviseurs privés plutôt qu'à des employés de la Commission bancaire. On constate toutefois, à l'analyse de l'évolution de son budget, que l'autorité de régulation parvient à développer les dimensions de son secrétariat de manière progressive et continue au cours des années d'après-guerre, au gré des nouvelles compétences et donc des nouvelles sources de revenus qu'elle obtient.

De plus, la Commission bancaire bénéficie d'une très large autonomie institutionnelle. Cette indépendance s'affirme non seulement à l'égard des instances gouvernementales, mais aussi vis-à-vis de la banque centrale, la BNB. Ses relations avec la BNB sont d'ailleurs marquées par une forte tension : les tentatives de collaboration sont rendues plus difficiles par la concurrence que se livrent les deux instances pour maintenir leur mainmise sur les domaines qu'elles estiment faire partie de leurs compétences exclusives.

Des arrangements institutionnels originaux des années 1930 découle en outre une troisième particularité. Les textes réglementaires de 1935 font en effet régner un grand flou sur les dispositifs grâce auxquels la Commission bancaire est supposée mettre en œuvre les principes fixés dans la législation. Ils sont particulièrement imprécis en ce qui concerne les moyens d'intervention. La réglementation fixe plutôt des missions générales, dont découlent implicitement des pouvoirs que s'arroge la Commission bancaire. L'action de conseil, la pression morale et autres interventions informelles qui rappellent la méthode $\mathrm{du}$ "sourcil relevé » du gouverneur de la Bank of England ("governor's eyebrows») constituent des méthodes privilégiées de l'action de la Commission bancaire, en particulier sous la longue présidence d'E. de Barsy (1944-1973). Ce dernier n’hésite pas à solliciter 
régulièrement des entretiens avec les grands pontes de la finance belge et à émettre des recommandations, parfois de manière appuyée, en vue de corriger ce qu'il considère comme une transgression ou une erreur. Comme le relève son ancien collaborateur H. Biron, pour E. de Barsy, « le rôle de la Commission bancaire devait être d'orienter les structures bancaires et financières, de conseiller, de pardonner ou d'admonester, plus rarement de réprimer. Son mode principal d'intervention était le dialogue avec l'administré ${ }^{207}$. Bénéficiant d'une longue expérience de professorat, E. de Barsy semble administrer le régime de contrôle bancaire avec une certaine autorité. La fréquence des contacts entretenus par le président de la Commission bancaire avec les dirigeants bancaires permet à l'organisme de gérer les éventuels contentieux avec une certaine souplesse, dans une logique de gentlemen's agreement. On peut résumer cette philosophie d'intervention très particulière en affirmant que la Commission bancaire a cherché à compenser par la voie de la recommandation et de la concertation les faiblesses d'une législation lacunaire.

En déplaçant sa force de persuasion sur un terrain qui n'est pas strictement juridique et normatif, l'organisme de régulation fait preuve d'une grande autorité et recherche souvent des solutions au-delà du seul cadre légal. Aussi n'est-il pas étonnant que la Commission bancaire ne soit jamais confrontée à un établissement qui conteste le bien-fondé d'une de ses décisions par la voie juridique, par exemple, sous la forme d'un recours devant le Conseil d'État ${ }^{208}$.

Parallèlement, en exploitant les rares outils contraignants dont elle dispose, la Commission bancaire parvient pendant la période de l'après-Seconde Guerre mondiale à s'établir comme un partenaire de négociation crédible et non négligeable, en particulier dans le dossier de la détermination des coefficients bancaires. En instaurant des ratios qui impliquent le placement automatique de dépôts pour alimenter le Trésor public, la Commission bancaire jouit d'un pouvoir exécutif qui a un impact immédiat et dont les effets dépassent la simple surveillance bancaire : politique monétaire, stabilisation des finances publiques, orientation des crédits bancaires. Il faut souligner que la Commission bancaire belge obtient ici une capacité d'influence significative auprès d'autres acteurs-clés de la politique économique nationale (Ministère des Finances, BNB). À cet égard, l'autorité de régulation bancaire jouit d'une réputation de magistrature économique d'importance, comme en témoigne également le parcours remarquable de certains de ses premiers collaborateurs.

Il faut enfin relever que la philosophie d'intervention très proche de la politique de concertation et de la négociation informelle n'est pas adoptée de manière unilatérale par la Commission bancaire. Cette approche rencontre aussi souvent l'adhésion des représentants des banques. En effet, les milieux bancaires, dans leurs négociations avec les autorités publiques, privilégient presque systématiquement la résolution d'un problème par le biais d'une solution relativement souple - règlement promulgué par l'autorité de surveillance, accord informel avec la banque centrale, etc. -, afin d'éviter le recours à une modification législative qui doit passer devant le Parlement. Le déplacement de la sphère de décision vers un espace largement dépolitisé et considéré comme un cénacle

207 H. BIRON, « Le président », in E. WYMEERSCH (dir.), In bono et aequitate perseverans. Baron de Barsy 19061985, Bruxelles, Bruylant, 1985, p. XXXIX.

${ }^{08}$ De tels recours contre des décisions de la CB n'ont jamais été pris entre 1946 et 1972 (cf. A. BRUYNEEL, "La Commission bancaire belge », op. cit., p. 15). 
d'experts que constitue la Commission bancaire permet d'éviter l'ouverture d'un débat public, dont la portée est beaucoup plus difficile à maîtriser pour les acteurs impliqués. En Belgique comme ailleurs, la notion de stabilité de l'environnement réglementaire est considérée comme essentielle pour les milieux bancaires et ceux-ci craignent les propositions trop progressistes qui pourraient survenir dans une sphère de décision ouverte aux profanes. Paradoxalement, le développement, au cours du $\mathrm{XX}^{\mathrm{e}}$ siècle, d'un régime de surveillance étatique sur les banques ne met pas un terme aux mécanismes d'autorégulation qui dominent dans ce secteur, mais a plutôt tendance à les renforcer. 


\section{CENTRE DE RECHERCHE ET D'INFORMATION SOCIO-POLITIQUES}

Le CRISP, Centre de recherche et d'information socio-politiques, est un organisme indépendant. Ses travaux s'attachent à montrer les enjeux de la décision politique, à expliquer les mécanismes par lesquels elle s'opère, et à analyser le rôle des acteurs qui y prennent part, que ces acteurs soient politiques, économiques, sociaux, associatifs, etc.

Par ses publications, le CRISP met à la disposition d'un public désireux de comprendre la société belge des informations de haute qualité, dans un souci d'exactitude, de pertinence et de pluralisme. Son objectif est de livrer à ce public les clés d'explication du fonctionnement du système socio-politique belge et de mettre en évidence les structures réelles du pouvoir, en Belgique et dans le cadre de l'Union européenne.

Le Courrier hebdomadaire paraît au rythme de 40 numéros par an, certaines livraisons correspondant à deux numéros. Chaque livraison est une monographie consacrée à l'étude approfondie d'un aspect de la vie politique, économique ou sociale au sens large. La revue du CRISP constitue depuis 1959 une source d'information incontournable sur des sujets variés : partis politiques, organisations représentatives d'intérêts sociaux et groupes de pression divers, évolution et fonctionnement des institutions, négociations communautaires, histoire politique, groupes d'entreprises et structures du tissu économique, conflits sociaux, enseignement, immigration, vie associative et culturelle, questions environnementales, européennes, etc. C'est également dans le Courrier hebdomadaire que sont publiés les résultats des élections commentés par le CRISP.

Les auteurs publiés sont soit des chercheurs du CRISP, formés en diverses disciplines des sciences humaines, soit des spécialistes extérieurs provenant des mondes scientifique, associatif et socio-politique. Dans tous les cas, les textes sont revus avant publication par le rédacteur en chef et par un groupe d'experts sélectionnés en fonction de la problématique abordée, afin de garantir la fiabilité de l'information proposée. Cette fiabilité, ainsi que la rigoureuse objectivité du Courrier hebdomadaire, constituent les atouts principaux d'une revue dont la qualité est établie et reconnue depuis près de 60 ans.

Fondateur : Jules Gérard-Libois

Président : Vincent de Coorebyter

Équipe de recherche :

Pierre Blaise (secrétaire général), Fabienne Collard, Vaïa Demertzis, Jean Faniel (directeur général), Christophe Goethals, Cédric Istasse, John Pitseys, David Van Den Abbeel (coordinateur du secteur Économie), Marcus Wunderle

Conseil d'administration :

Louise-Marie Bataille, Jacques Brassinne de La Buissière (vice-président honoraire), Vincent de Coorebyter (président), Francis Delpérée, Hugues Dumont, Éric Geerkens, Nadine Gouzée, Serge Govaert, Laura Iker, Patrick Lefevre, Michel Molitor (vice-président), Solveig Pahud, Pierre Reman, Robert Tollet (vice-président), Els Witte, Paul Wynants 


\section{Derniers numéros du Courrier hebdomadaire parus}

2357-2358 Formation et spécificités historiques de la Commission bancaire (1935-1975)

Thibaud Giddey

2355-2356 La Ligue des familles (1950-1975)

Élodie Tallier

2353-2354 Le Processus de Kimberley et la lutte contre le commerce des « diamants de sang» Élise Rousseau

2352 Le projet de Centre de formation pour sportifs de haut niveau (CFSHN) Jérôme Defosse

2350-2351 L'autonomie constitutive des entités fédérées Quentin Peiffer

2348-2349 La régulation publique de la biomédecine. Procréation médicalement assistée, recherche sur embryons, gestation pour autrui Nathalie Schiffino

2346-2347 Distribution et redistribution des revenus : évolution des inégalités en Belgique Christian Valenduc

2344-2345 Le G1000 : une expérience citoyenne de démocratie délibérative M. Reuchamps, D. Caluwaerts, J. Dodeigne, V. Jacquet, J. Moskovic et S. Devillers

2343 Le profil des parlementaires néerlandophones en 2015 Jef Smulders

2341-2342 Grèves et conflictualité sociale en 2016 Iannis Gracos

2339-2340 L'évaluation des pôles de compétitivité wallons : méthodes, résultats et mise en perspective européenne C. Dujardin, P. Lefebvre, M. Lefèvre, V. Louis, F. Pallez et F. Vanderkelen

2337-2338 Les pôles de compétitivité wallons : dix ans de politique industrielle C. Dujardin, P. Lefebvre, M. Lefèvre, V. Louis, F. Pallez et F. Vanderkelen

La collection intégrale du Courrier hebdomadaire est accessible sur www.cairn.info. L'accès est gratuit pour les numéros parus avant 2016.

Découvrez notre catalogue complet incluant nos autres publications sur www.crisp.be.

Pour être informé de nos publications dès leur parution, inscrivez-vous en ligne à notre lettre d'information électronique. 